\title{
Natural Resources for Human Health
}

\section{Review}

View Article Online

Check for updates

Received 05 September 2021

Revised 04 November 2021

Accepted 05 November 2021

Available online 10 November 2021

Edited by Jialin Xu

\section{KEYWORDS:}

COVID19

Diabetes

Hyperglycemia

Cytokine storm

Herbs-spices

Natr Resour Human Health 2022; 2 (1): 32-51 https://doi.org/10.53365/nrfhh/143758 eISSN: 2583-1194

Copyright $(2022$ Visagaa Publishing House

\section{Herbal spices-based therapeutics for diabetic patients with COVID-I 9 infection: A review}

\author{
Rajasekar Panchamoorthy ${ }^{1,},{ }^{*}$ Nethra Vel ${ }^{1}$ \\ ${ }^{1}$ Department of Biotechnology, Rajalakshmi Engineering College, Thandalam, 602105, Chennai, \\ India
}

\begin{abstract}
The COVID-19 pandemic is a highly challenging situation and affects people's lives severely. Nowadays, the original coronavirus gets mutated into different variants and infects all age groups. Elderly people with comorbidities like diabetes are highly susceptible to coronavirus infection due to poor glycemic control, and immunity. The mechanism of COVID-19 infection is not fully understood. However, the scenario of current infection is similar to the history of pandemics that the world faced earlier (i.e.) the persisted hyperglycemia is considered as the major root cause of severe viral infections. The uncontrolled hyperglycemia can produce lowgrade inflammation and impaired immunity mediated cytokine storm that can cause multiple organs failure and sudden death in diabetic patients with COVID-19 infection. The available hypoglycemic and antiviral drugs and vaccines are not sufficiently efficient against COVID19 and also cause several side effects. As the traditional medicines are considered life-saving drugs for various human diseases, the present review has analyzed the herbs-spices with antiviral, antidiabetic, antioxidant, anti-inflammatory, and immunomodulatory properties. The intake of this herbal-spices formulation could exert both therapeutic and prophylactic effects against the COVID-19. However, the proper scientific studies are necessary for the validation of its efficacy and mode of action against COVID-19.
\end{abstract}

\section{INTRODUCTION}

Diabetes is a multi-metabolic disorder mainly due to an impaired insulin release or a defective insulin action, or both (i.e.) variety of nutrient (carbohydrates, lipids, and proteins) metabolisms get affected in diabetes mainly due to the impaired insulin actions and accompanied with various metabolic impairments [hyperglycemia, impaired glucose tolerance, hyperinsulinemia, dyslipidemia] and other life-threatening complications [micro and macrovascular complications, oxidative stress, diabetic nephropathy, diabetic neuropathy, etc.] (Eckel et al., 2005). There are two types of diabetes namely type 1 diabetes and type 2 diabetes (T2D) based on the action of insulin. Type 1 diabetes (T1D) results from the complete absence of insulin secretion, whereas an inadequate insulin secretion and resistance to insulin action cause type 2 diabetes.

\subsection{Prevalence of diabetes}

Globally, people are suffering from diabetes in the $21^{\text {st }}$ century. It is considered the fifth leading causative factor of mortality (Punthakee et al., 2018). The prevalence of T2D is higher than T1D, which accounts for $90 \%$ of the total diabetic population. Worldwide, 171 million people are affected by diabetes and expected to increase more than two folds in 2030. The International Diabetes Federation (IDF) and IDF Atlas have been surveyed in 2015 and 2017, respectively, and reported about 415 and 451 million people affected by diabetes, respectively. It is expected to increase by 640 to 693 million in both developed and developing countries by the year 2045 (Ogurtsova et al., 2017). This infers that the prevalence of diabetes could increase several folds in the successive survey periods. Moreover, the World Health Organization (WHO) has stated 36 million annual mortalities associated with noncommunicable diseases. About 1.3 million deaths are due to diabetes and its complications (Ogurtsova et al., 2017). Recently, the worldwide mortality due to diabetes has been increased to 5 million (Cho et al., 2018).

\subsection{Pathophysiological mechanisms and management of diabetes}

It has been suggested that there are eight pathophysiological mechanisms underlying T2D (Defronzo, 2009), which include poor/reduced insulin secretion, insulin resistance, increased glucagon secretion, promoted hepatic glucose production, defective/impaired glucose utilization/uptake in peripheral tissues (liver, muscle, $\&$ adipose tissue), reduced gut hormone (incretin) action, increased glucose reabsorption in the kidney, and elevated lipolysis. Based on these key pathophysio-

\footnotetext{
* Corresponding author.

E-mail address: rajasekar.panchamurthy@gmail.com (Rajasekar Panchamoorthy)
} 
logical mechanisms, the available antidiabetic drugs target one/more key pathways. Currently, biguanides, dipeptidyl peptidase 4 inhibitors, sodium-glucose cotransporter inhibitors, thiazolidinedione, sulfonylureas, $\alpha$-glucosidase inhibitors, and meglitinide are used as oral antidiabetic medications. T2D has been treated by pharmacological agents when the glycemic control is not achieved or the glycated hemoglobin (HbA1C) level increased to $6.5 \%$. Combination therapy of two oral agents or with insulin therapy is considered when the HbA1C level gets raised to $7.5 \%$ or its initial level persisted above 9\% (Chamberlain et al., 2016). This suggests that the management of diabetes involves either oral hypoglycemic agents or exogenous insulin therapy based on the severity of glycemic control. Although the available therapeutic compounds are widely used for the treatment of diabetes, they are accompanied with several side effects (Ghorbani, 2013). For example, long-term insulin therapy causes fatty liver, insulin resistance, fatty liver, anaeroxia nervosa, etc. Additionally, oral hypoglycemic drugs also exert several side effects including abdominal discomfort, lactic acidosis, hypoglycemia, peripheral edema, etc. (Ghorbani, 2013).

\subsection{Impacts of diabetes on the immunity}

Marked hyperglycemia and insulin deficiency can affect cellular immunity (Berbudi et al., 2019). For example, the non-healing diabetic foot infection is mainly due to the defective blood supply and poor immunity mediated limited access of phagocytic cells/macrophages in the wound area (Frykberg \& Banks, 2015). Furthermore, hyperglycemia impairs immunoglobulin-mediated opsonization, neutrophil degranulation, and its extracellular traps (Tessaro et al., 2017). It also affects the functions of $\mathrm{T}$ lymphocytes (adaptive immune response). Apart from this, the high glucose environment favors microbe growth and helps them become more virulent (Geerlings \& Hoepelman, 1999).

Moreover, the administration of insulin has been restored the phagocytic action of alveolar macrophages. It also normalized the increased production of tumor necrosis factor-alpha (TNF$\alpha$ ) and interleukin 6 (IL-6) in the isolated bone marrow-derived macrophages of diabetic mice (Tessaro et al., 2017). Several in vitro studies revealed the lower production of interleukin12 (IL-12) and interferon-gamma (IFN- $\gamma$ ) and higher bacterial load in the infected peripheral blood mononuclear cell (PBMC) culture of diabetic subjects than compared to the PBMC culture of healthy people. Whereas, the bacterial load was reduced in the treated PBMC culture with the recombinant IL-12 and IFN- $\gamma$ (Tan et al., 2012).

Zinc plays a crucial role in the regulation of immunity and inflammation. For example, it has been observed that proliferation, maturation, and survival of various immune cells (monocytes, natural killer-, polymorphonuclear-, B-, and $\mathrm{T}$ - cells functions) are affected in acute zinc deficiency. It infers that acute zinc deficiency can affect both innate and adaptive immunity. Whereas, chronic zinc deficiency promotes inflammation through the increased production of pro-inflammatory cytokines (Bonaventura et al., 2005) . Apart from this, the deficiency of zinc also disturbed the response of lymphocytes and chemotactic action in the diabetic patients derived polymorphonuclear cells (PMNs).

Moreover, zinc also plays important role in the beta and alpha-cells of the pancreas for the secretion of insulin and glucagon. Zinc maintains the phosphorylation of insulin receptors and mediates downstream insulin signaling by inhibiting protein tyrosine phosphatase 1B (Maret, 2017). The importance of zinc has been proven in both type 1 and type 2 diabetic subjects and its level has been reduced in diabetic patients (Geerlings \& Hoepelman, 1999). Furthermore, zinc deficiency is associated with insulin resistance and glucose intolerance (Cruz et al., 2018). It also exacerbates oxidative stress, triggers inflammation, and causes immunosuppression. The supplementation of zinc has been potentially improved insulin sensitivity, reduced oxidative stress, protected the kidney from damage, reduced the levels of glucose, HbA1c, and lipids in prediabetes and diabetic subjects (Poudel et al., 2017). However, it has been suggested that more intervention studies are warranted to conclude whether zinc supplementation prevents type 2 diabetes (Maret, 2017). This suggests that hyperglycemia and impaired zinc levels can attenuate cellular innate immunity and adaptive immunity in diabetic conditions. Furthermore, chronic hyperglycemia and impaired insulin sensitivity mediated inflammatory and peroxidative states are considered as the major pathological elements of immunosuppression, which represents a higher risk of infection, and associated mortality in T2D (Gupta et al., 2020). The proper management of hyperglycemia and insulin action can restore immune cell functions and thereby eliminate infections/microbial load effectively.

\section{HISTORY OF PANDEMICS AND OVERVIEW OF NOVEL CORONAVIRUS 2019}

The world faced pandemics due to the infection of severe acute respiratory syndrome coronavirus (SARS-CoV) and Middle East respiratory syndrome coronavirus (MERS-CoV) in 2002 and 2012, respectively. In 2019, SARS-COV2 infection to humans was first identified in Wuhan, China, and continued to spread worldwide very rapidly (R. Lu et al., 2020; Song et al., 2019). The natural reservoir of SARS-CoV and MERS$\mathrm{CoV}$ were of bats. Whereas, the zoonotic origin of SARS$\mathrm{CoV} 2$ is still not clear. However, it shows a wide range of nucleotide similarities (96\%) with RaTG13 virus present in the horseshoe bat, Rhinolophus affinis. Thus, bats are considered a natural reservoir of the SARS-CoV2 virus (Joshi et al., 2013). This novel SARS-CoV2 induced disease is provisionally named as the coronavirus disease 2019 (COVID 2019). Because of its massive infection and increasing worldwide death rate, the WHO announced the COVID-19 is an ongoing pandemic.

The novel coronavirus belongs to the family of Coronaviridae and subfamily of Orthocoronavirinae (Gorbalenya et al., 2020; Joshi et al., 2013). There are four genera, namely alpha, beta, delta, and gamma coronavirus under the subfamily of 
Orthocoronavirinae. The first two can widely infect mammals, whereas the latter two infect avian species (Fan et al., 2019). The novel coronavirus is an RNA virus. It contains a single-stranded RNA and spike proteins on its envelope. The spike proteins show a high affinity towards the angiotensin-converting enzyme 2 (ACE 2) receptor of host cells (Figure $\mathbf{1}$ ).

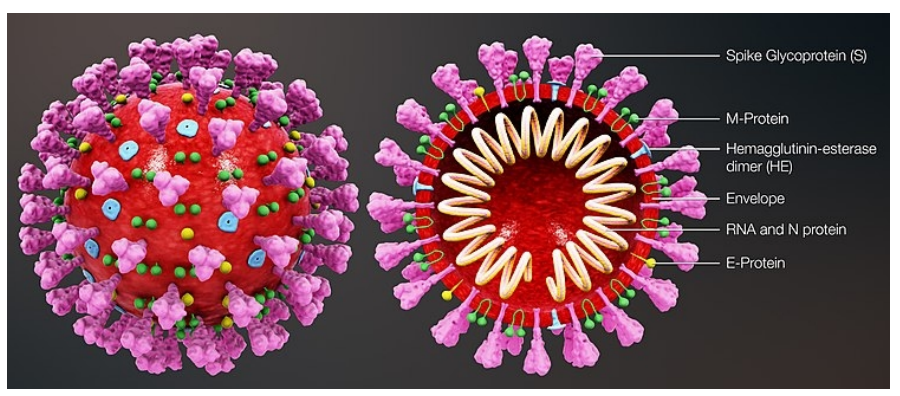

Figure 1. The morphology and structure of SARS-CoV-2

ACE 2 receptor has been expressed in most cells, tissues, and pancreatic islets in humans (Wang et al., 2015). Therefore, this virus can easily reach the target cells of the host and cause infection. This novel coronavirus can affect all age groups, especially elderly people with poor immunity. Its infection is associated with various symptoms such as dry cough, fever, fatigue, sore throat, headache, vomiting and diarrhea, dyspnea, and lymphopenia (J.J. Zhang et al., 2020). The clinical characteristics of COVID-19 are similar to the MERS-CoV and SARS-CoV (C. Huang et al., 2020).

\subsection{Risk factors for COVID-19}

Individuals with other medical complications like diabetes and high blood pressure are considered as the major risks for infection of the novel coronavirus. The increased intake of the Western diets (i.e.) diet with either high amounts of saturated fats, refined sugars/carbohydrates, least fiber contents, antioxidants, or unsaturated fats can cause T2D and obesity, which can worsen immunity, increase the risk of coronavirus infection, trigger other complications and increase the rate of mortality (de Frel et al., 2020). It is evident that the death rate of diabetic patients with the COVID-19 infection has been increased 2-3 times when compared to the COVID19 infected patients without diabetes (N. Chen et al., 2020). Furthermore, the intensive care unit (ICU) admission has been drastically increased for the COVID-19 infected diabetic patients (Roncon et al., 2020). Apart from this, hyperglycemia has been considered as an independent causative factor for death in previously experienced disease epidemics. The same has been experienced for COVID-19 also (B. Li et al., 2020). It is also evident that hyperglycemia has been associated with the worst chest conditions observed from the radiographic imaging of COVID-19 patients (Iacobellis et al., 2020). Furthermore, uncontrolled hyperglycemia has been considered a major risk factor for various outcomes such as ICU admission, ventilation, and death in the COVID-19 patients without diabetes as compared to diabetic patients with normoglycemia (Y. Zhang et al., 2020). It is also stated that the severe COVID-19 infection has been increased the prevalence of diabetes (Guan et al., 2020). This suggests that the coronavirus exerts its harmful effect on normal individuals via disturbing the normal glucose homeostasis. Therefore, the infection of coronavirus is more severe in diabetic subjects with poor management.

\subsection{Coronavirus infection mediated cytokine storm and multi-organ failure in diabetic subjects}

The novel coronavirus affects circulating immune cells (T lymphocytes with different markers (i.e) CD3, CD4, and CD8 $T$ cells and B lymphocytes) and cells of the respiratory system (N. Chen et al., 2020). This infers that COVID-19 infection can abolish both the adaptive and innate immunity, which eventually triggers the overproduction of pro-inflammatory cytokines such as TNF $\alpha$, IL-6, interleukin 1 beta (IL-1 $\beta$ ), and CXC-chemokine ligand-10 (Qin et al., 2020). These can recruit other immune cells and thereby causing the worst condition referred to as "cytokine storm", which eventually leads to cause vascular hyperpermeability, fluid retention in alveoli and respiratory trouble/impaired pulmonary function, multiorgan failure, and sudden death in COVID19 infection (Ragab et al., 2020) . Generally, diabetes has been associated with low-grade chronic inflammation. This condition could be aggravated by an impaired adaptive and innate immunity mediated cytokine storm and this might account for multi-organ failure and death in COVID-19 patients with diabetes. Moreover, the coronavirus-infected diabetic patients have been displayed a higher rate of erythrocyte sedimentation and increased levels of inflammatory biomarkers such as IL-6, serum ferritin, and C-reactive protein (Guo et al., 2020).

\subsection{Side effects of drugs used for diabetic patients with COVID-19}

Various glucose-lowering agents have been used for COVID19 patients with diabetes. However, patients with uncontrolled diabetes/very poor glycemic control with COVID-19 are treated by insulin with the replacement of existing glucose-lowering therapies. Insulin therapy is mainly based on various factors such as nutritional status, glycemic index, the severity of COVID-19 infection, risk of hypoglycemia, drug interaction, and renal function. However, insulin therapy has been exerted undesirable clinical conditions and laboratory results in the severely infected COVID-19 patients with diabetes when compared to the glucose-lowering agent, metformin (Y. Chen et al., 2020). Moreover, it has been hypothesized that metformin may hinder the entry of the virus into target cells through the regulation/activation of various signaling molecules like adenosine monophosphate-activated protein kinase (AMPK), etc. (Sharma et al., 2020). However, the drug, metformin is not advised to take patients with heart failure, kidney dysfunction, or respiratory problem due to the risk of lactic acidosis (Bornstein et al., 2020).

The co-administration of acetylsalicylic acid and corticosteroids or acetylsalicylic acid and heparin to severe COVID- 
19 patients may increase the risk of gastrointestinal bleeding or ulcer. Statin has been considered at the stage of multiorgan damage associated with severe viral infection (Driggin et al., 2020). However, statin treatment may also worsen the clinical conditions with the risk of myopathy and liver damage. In addition, the use of statin with lopinavir, the antiviral protease inhibitor can exert drug interaction in addition to its other risk (Bangash et al., 2020). Currently, COVID19 patients are frequently treated with a high dose of broadspectrum antiviral drugs (remdesivir, ritonavir/lopinavir, and chloroquine) and antibodies for speedy recovery/cure from the infection. However, most of the drugs produce harmful effects and cause severe complications. For example, the frequently treating antiviral drugs like remdesivir show mixed results with breathing problems (A.K. Singh et al., 2020). Other antiviral drugs such as ritonavir/lopinavir can cause kidney dysfunction and hyperglycemia. In addition, the use of chloroquine/hydroxychloroquine affects mental health and causes hypoglycemia (Ullah et al., 2021). Several new organic compounds including cyanorona-20, a new favipiravir derivative also synthesized and evaluated its anti-COVID-19 potency through various in vitro and computational studies. This study suggested that the sequence of in vivo studies and clinical trials are warranted to confirm cyanorona-20 as an antiCOVID-19 drug (Rabie, 2021a, 2021b) .

The anti-inflammatory action of pioglitazone has been well documented. It inhibits the secretion of pro-inflammatory cytokines and increases the anti-inflammatory cytokines. It also reduces the inflammation in lung tissue and fibrosis in animals (Qiu \& Li, 2015). However, the use of pioglitazone in COVID-19 patients with diabetes has been associated with deleterious effects such as fluid retention, edema, and heart failure (Carboni et al., 2020). Steroids have been employed to treat COVID-19 patients with severe pulmonary infection. Though steroids protect people from cytokine stormmediated multi-organ failure, in later cases, steroids treatment can produce life-threatening deleterious consequences such as pneumonia, blood clotting, diabetogenic effect, and multiorgan failure. Recently, it has been observed that steroid therapy can cause mucormycosis (black fungal infection) and sudden death in diabetic subjects. This infers that the available drugs (antidiabetic, antiviral, and anti-inflammatory drugs) are not good enough to fight against the infection of COVID-19 and also produce various health hazards, especially in diabetic patients with poor/lack of immune response. Furthermore, it also suggests that there is a need for an efficient drug with multi-therapeutic actions such as anti-viral, anti-hyperglycemic, anti-inflammatory, and immunomodulatory properties for the treating of COVID-19 infected patients with or without diabetes.

\subsection{Impacts of vaccines against the coronavirus infection}

Various countries are putting effort to develop vaccines to control the infection of coronavirus. The efficiency of vaccines and impacts of vaccination must be addressed for the emerging variants of coronavirus. Recently, WHO has been explained, the importance of vaccination even if vaccines have less effective against some of the new variants of coronavirus and also suggested vaccination may give some kind of protection against new variants. The recent virtual press conference of WHO on COVID-19 on $10^{\text {th }}$ May 2021 stated that India has been faced an explosive outbreak due to the spreading of a highly contagious double mutant strain, B.1.617. This variant more easily spreads than the original strain of coronavirus that was found very first in India. Also suspected that this new strain might be increased its resistance against vaccines. Thus, the WHO has stressed that the behavior of the B.1.617 strain must be studied among the vaccinated and unvaccinated people in India and other countries. WHO also again pinpointed that the continuing of safety measures like frequent hand washing, social distancing, mask-wearing, etc. can work against new variants transmission and also reduce the opportunities of the virus to mutate. Nowadays, the mutated COVID-19 strain infects more in children, adults, and old age people with no other medical complications and also increases mortality. As of now, there is no proper module to treat this deadly infection. This suggests that there is a need to develop highly effective vaccine(s) and antiviral drugs against the mutated variants of coronavirus. It also clearly reveals that prevention is better than cure.

\section{IMPORTANCE OF TRADITIONAL HERBS-SPICES IN HEALTH CARE}

The traditional medicinal herbs/plants and spices are considered as the alternative source of life-saving therapeutics against various deadly diseases. The Indian traditional medicine system plays a major role in combating various illnesses of humans and also acts as the best resource for revealing bioactive lead molecules for the fulfillment of health care needs worldwide. The Indian traditional medicine system consists of various branches such as Siddha, Ayurveda, Unani, Yoga, Homeopathy, and Naturopathy. All of these treatment systems involve herbs, medicinal plants, spices, animal products, minerals, etc. Most of the medicinal herbs/plants and spices are of Indian origin, thus India is considered as home to medicinal plants/herbs and spices. It is evident that the WHO has recognized and recommended 21,000 medicinal plants for the use of various medicinal purposes. Of these, 2500 species are in India. Among these 150 species are commercially used on large scale (Bhagyasri et al., 2018). Moreover, the traditional health care systems have been explored the health benefits of herbs and used for the treatment of various disorders such as diabetes, anemia, pain, gastrointestinal problems, helminthiasis, respiratory tract problems, jaundice, tooth and gum problems, skin diseases, and allergy (Mohiuddin, 2019). For example, more than twenty-five thousand herbal formulations have been used in folk medicines (Pundarikakshudu \& Kanaki, 2019).

Spices are the dried material of any parts (root, bark, buds, flowers, fruits, or seeds) of plants that contain volatile oil/aromatic fragrance and flavors. Spices impart various flavors (chilly, sour, bitter, and sweet) to food; especially Indian 
food tastes fully depend upon different spices (M. Gupta, 2010). Apart from this, traditionally, spices are used as expectorants, appetizers, digestives, carminatives, laxatives, purgatives, diuretics, etc. In addition, spices also protect from various acute and chronic diseases (Sanlier \& Gencer, 2020). Furthermore, the inclusion of medicinal herbs and spices in the food can also improve immunity and protect against various causative agents. The famous Tamil quote says "Unavae marunthu. Marunthae unavu"; In the English language, it means that food is medicine and medicine is food.

\subsection{Reasons for the selection of phytotherapeutics in health care}

The beneficial impacts of ancient medicinal plants have been accompanied by their various secondary metabolites such as polyphenols, flavonoids, alkaloids, terpenoids, glycosides, etc. (Wink, 2015). This infers that an individual medicinal plant/herb possesses plentiful bioactive phytochemicals, that may act individually or collectively and thereby exert desired pharmacological effects (Hussein \& El-Anssary, 2018). The isolated active constituents are used as phytotherapeutics against various diseases and also served as a template for the synthesis of pharmaceutical drugs. Thus, traditional medicine is considered as a substitute for usual conventional drugs. Now a day's people are willing to take a single drug with multiple actions instead of multiple drugs for different health complications. More than $80 \%$ of people in both developing and developed countries fully depend upon traditional herbal medicines for their primary health care. Because, herbal medicines offer multiple therapeutic effects without other side effects/complications (Baell, 2016). Additionally, herbal therapeutics also offer numerous advantages in various aspects such as the possibility for mass production/cultivation, chief, availability, non-toxic, environment friendly, etc. (Kazi, 2014).

\subsection{The available traditional therapeutics against the coronavirus infection}

The Indian traditional health care system, AYUSH (Ayurvedic-Yoga and Naturopathy-Unani-Siddha and Homeopathy) suggested an extract called Kadha, which is prepared from the dried spices and herbs and suggested to drink COVID-19 patients for the promoting of immunity. Furthermore, AYUSH also recommended the warm water extracts of different herbal plants such as Andrograhis paniculata (for cold and fever), Tinospora cordifolia (for Chronic fever), Cordia myxa, Cydonia oblonga, and Zizyphus jujube (for multiple therapeutics effects including anti-influenza, antioxidant, antiallergic, immunomodulatory and smooth muscle relaxant activities) to COVID-19 patients. Moreover, Traditional Chinese medicine (TCM) used the extracts of Sanctellaria baicalensis and tangerine peel for the treatment of COVID19 and considered that baicalin of Sanctellaria baicalensis and hesperetin of tangerine peel extracts are the prime bioactive constituents for the curing of COVID-19 symptoms (H. Liu et al., 2021). In addition, the decoction prepared from Zingiber officinale Roscoe (Sunthi), Syzygium aromaticum (Lavanga), and Piper nigrum (Maricha) has been advised to take infected and healthy individuals for the improvement of cell-mediated and humoral immunity and also for the reduction of nasal congestion and hyperresponsiveness in airways (Bui et al., 2020).

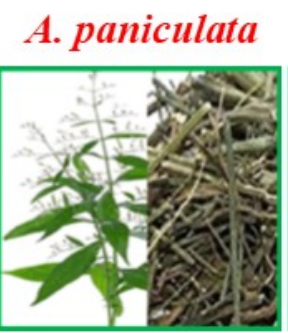

G. glabra

A. indica

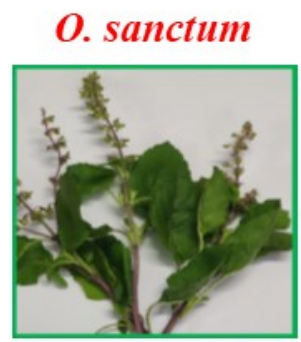

M. oleifera
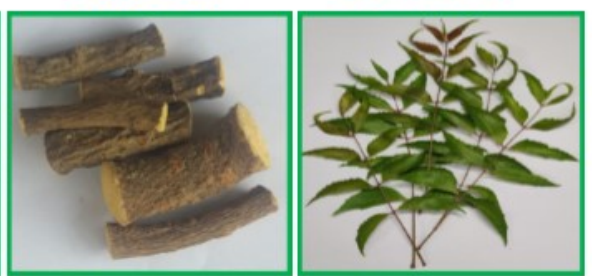

Piper betel

M. koenigii
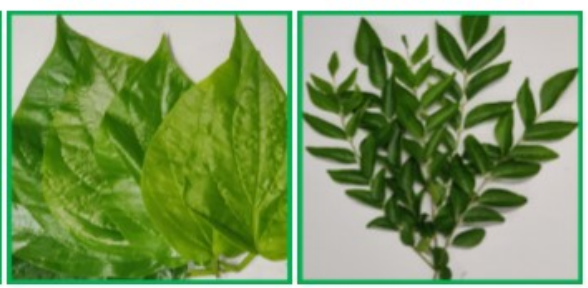

P. emblica

Citrus limon
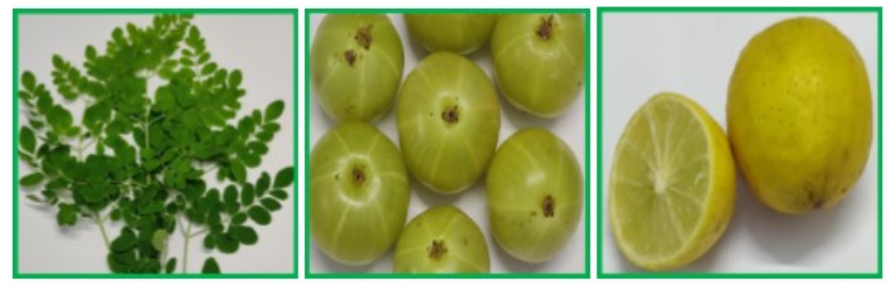

C. cyminum

P. nigrum

C. longa
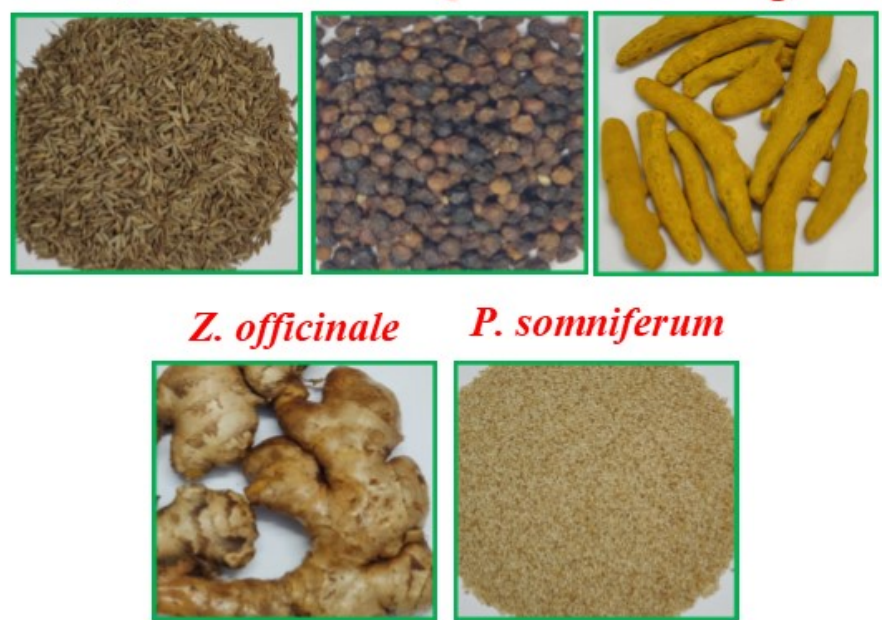

Figure 2. Photographic images of the proposed herbs and spices against the COVID-19. A. paniculata-Andrographis paniculata; G. glabraGlycyrrhiza glabra; O.sanctum- Ocimum sanctum; M. koenigii- Murraya koenigii; M. oleifera-Moringa oleifera; P. emblica-Phyllanthus emblica; C.cyminum-Cuminum cyminum; P. nigrum- Piper nigrum; C. longaCurcuma longa; Z. officinale-Zingiber officinale; P. somniferum- Papaver somniferum. 
The possible antiviral, antidiabetic, antioxidant, anti-inflammatory, and immunomodulatory activities of the selected herbs and spices therapeutics against the COVID-19 infection in diabetic and normal subjects

\section{S. No. Scientific \& common names and family of herbs \& spices}

1. Andrographis paniculata (AP) Common name: Creat or Green chiretta Family: Acanthaceae

Andrographolide

Neoandrographolide AP (Nilavembu Kudineer)

2. Glycyrrhiza glabra (GG) Common name: Licorice Family: Fabaceae

GG

GG

Glycyrrhizic acid

Glycyrrhizic acid, Liquiritigenin \& Glabridin

3. Azadirachta indica (AI) Common name: Neem Family: Meliaceae
AI

AI phytochemicals

AI phytochemicals

$\mathrm{AI}$ and its active compounds
Pharmacological activities of herbs $\&$ spices

Represses the pathogenesis of SARS-CoV and SARS-CoV-2 (F. Liu et al., 2020).

Corrects the symptoms of acute respiratory tract infections (Hu et al., 2017).

Anti-dengue activity against Dengue-2 virus (Kaushik et al., 2021).

Acts as the best natural antioxidant (Mussard et al., 2019).

Regulates Nrf2 signaling and enhances the activities of endogenous antioxidants (Mussard et al., 2019).

Reduces oxidative stress and shows antidiabetic activity (Dai et al., 2019).

Inhibits NF-kB and shows anti-inflammatory activity (Dai et al., 2019).

Potency against SARS-CoV-2 virus (Murugan et al., 2021).

Promotes immunity. Acts against ACE2 enzyme receptor which facilitates coronavirus entry (Walter et al., 2020).

Antiviral activity against a wide range of viruses (Fiore et al., 2008).

Induce the interferons formation in humans (Sudhakar et al., 2021).

Inhibits HIV proliferation and displays immune activation (Sun et al., 2019).

Depict non-covalent interactions with the active site amino acids of the main protease of SARS-CoV2. Glycyrrhizic acid shows a high binding affinity. (Srivastava et al., 2020). Antiviral and anti-inflammatory activities (Ashfaq et al., 2016).

Disturbs RNA-dependent RNA polymerase (Balakrishna et al., 2021).

Dock with the main protease of SARS-CoV-2 (Umar et al., 2021).

Anti-diabetic and sucrase enzyme inhibitory activities (Abdelhady et al., 2016; Pingali et al., 2020). 


\begin{tabular}{|c|c|c|c|}
\hline \multicolumn{4}{|c|}{ Table 1 continued } \\
\hline 4. & Ocimum sanctum (OS) Common name: Holy & OS & Improves immunity and fight against viruses (Patel, 2020). \\
\hline & & $\begin{array}{l}\text { Beta-carotene, eugenol and } \\
\text { caryophyllene }\end{array}$ & $\begin{array}{l}\text { Show strong binding energy score on docking with } \\
\text { SARS-CoV-2 spike protein (Abdelhady et al., 2016). }\end{array}$ \\
\hline \multirow[t]{3}{*}{5.} & $\begin{array}{l}\text { Piper betel Common name: Betel Family: } \\
\text { Piperaceae }\end{array}$ & Aurantiamide & $\begin{array}{l}\text { Inhibits coronavirus due to its chymotrypsin-like-proteases } \\
\text { like activities. (Sengupta, 2020) }\end{array}$ \\
\hline & & $\begin{array}{l}\text { Piperol, caryophyllene, chavibetol, } \\
\text { catechol, betlol, eugenol, etragol, } \\
\text { quercetin etc. }\end{array}$ & $\begin{array}{l}\text { Improves self-defense mechanism against the } \\
\text { coronavirus. (Sengupta, 2020) }\end{array}$ \\
\hline & & Eugenol & Antioxidant activity (Aara et al., 2020) \\
\hline \multirow[t]{3}{*}{6.} & $\begin{array}{l}\text { Murraya koenigii (MK) Common name: Curry } \\
\text { tree Family: Rutaceae }\end{array}$ & MK & $\begin{array}{l}\text { Regulates blood glucose and promotes insulin } \\
\text { biosynthesis (Bi et al., 2017). }\end{array}$ \\
\hline & & MK leaves & $\begin{array}{l}\text { Used in folk medicine for the treatment of inflammation, } \\
\text { renal problem \& diabetes (Ganesan et al., 2013). }\end{array}$ \\
\hline & & $\begin{array}{l}\text { Leaves, roots, and bark (contain a } \\
\text { major amount of carbazole alkaloids) }\end{array}$ & $\begin{array}{l}\text { Antioxidant, antidiabetic, anti-inflammatory activities, } \\
\text { etc. (Balakrishnan et al., 2020). }\end{array}$ \\
\hline \multirow[t]{2}{*}{7.} & $\begin{array}{l}\text { Moringa oleifera } \\
\text { Common name: Drumstick tree Family: } \\
\text { Moringaceae }\end{array}$ & $\begin{array}{l}\text { Niaziminin and flavonoids } \\
\text { (isorhamnetin, kaempferol and } \\
\text { apigenin) }\end{array}$ & $\begin{array}{l}\text { Show the strongest interaction with the main protease of } \\
\text { SARS-CoV-2 (Sen et al., 2021; Shaji et al., 2021). }\end{array}$ \\
\hline & & $\begin{array}{l}\text { Vitamin c, A, B complex vitamins, and } \\
\text { minerals }\end{array}$ & $\begin{array}{l}\text { Antioxidant, immunomodulatory, and anti-inflammatory } \\
\text { activities (Kurokawa et al., 2016; Padayachee \& Baijnath, } \\
\text { 2020) }\end{array}$ \\
\hline \multirow[t]{3}{*}{8.} & $\begin{array}{l}\text { Phyllanthus emblica (PE) Common name: } \\
\text { Indian gooseberry Family: Phyllanthaceae }\end{array}$ & PE & $\begin{array}{l}\text { Exerts multiple actions against T2D (H.Z. Huang et al., } \\
\text { 2021). }\end{array}$ \\
\hline & & PE extract & Inhibit NF-kB (Kim et al., 2010). \\
\hline & & Fruits ingredients & $\begin{array}{l}\text { Antioxidant, anti-inflammatory, antioxidant activities, } \\
\text { etc. (Lakshmi et al., 2020). }\end{array}$ \\
\hline \multirow[t]{3}{*}{9.} & $\begin{array}{l}\text { Citrus limon (CL) Common name: Lemon } \\
\text { Family: Rutaceae }\end{array}$ & $\mathrm{CL}$ & Inhibits COVID-19 pathogenesis (Jalali et al., 2021). \\
\hline & & CL ( lemon favedo extract) & $\begin{array}{l}\text { Shows antioxidant and carbohydrate hydrolyzing enzymes } \\
\text { inhibiting activities (S.Y. Lu et al., 2021) }\end{array}$ \\
\hline & & Vitamin $\mathrm{C}$ and minerals & $\begin{array}{l}\text { Antioxidant, immune potentiation, and anti-inflammatory } \\
\text { activities (Klimek-Szczykutowicz et al., 2020) }\end{array}$ \\
\hline 10. & $\begin{array}{l}\text { Cuminum cyminum Common name: Cumin } \\
\text { Family: Piaceae }\end{array}$ & $\mathrm{CC}$ & $\begin{array}{l}\text { Displays antidiabetic activity. Protects the cells of the } \\
\text { pancreas. Increase insulin release and glycogen storage. (Bi } \\
\text { et al., 2017). }\end{array}$ \\
\hline
\end{tabular}

Continued on next page 
11. Piper nigrum Common name: Black pepper

Family: Piperaceae

12. Curcuma longa Common name: Turmeric or Indian saffron Family: Zingiberaceae

\section{Curcumin}

13. Zingiber officinale Common name: Ginger Family: Zingiberaceae

14. Papaver somniferum Common name: Opium Poppy Family: Papaveraceae extract, powder, or isolated bioactive

\section{PN}

$\mathrm{PN}$ is regarded as the "King of spices". Bioactive compounds with pharmaceutical and nutraceutical applications.

CL \& it's polyphenols

extract, powder, or isolated bioactive

Phytochemical compounds of Zingiber officinale and Citrus medica.

Alpha-linolenic acid Tocopherols and tocotrienols Minerals (copper,

magnesium, zinc, iron, manganese, and phosphorus)
Antidiabetic activity. Improves the antidiabetic activity of other spices. (Bi et al., 2017).

Antioxidant, antidiabetic, hypolipidemic, analgesic, anti-inflammatory activities, etc. (Takooree et al., 2019).

Improves impaired carbohydrate metabolism through its multiple actions (Beidokhti \& Jäger, 2017).

Blocks pro-inflammatory cytokines (IL-1, IL-6, and TNF-alpha) release (Omar et al., 2010).

Corrects inflammatory condition (anti-inflammatory activity) (Morvaridzadeh et al., 2020).

Corrects inflammatory condition (anti-inflammatory activity) (Morvaridzadeh et al., 2020).

Shows remarkable in silico affinity with the coronavirus spike protein and ACE-receptor (Haridas et al., 2021).

Antioxidant, anti-inflammatory, immunomodulatory, various proteinase inhibitory activities (Kroslak et al.,

2017) . Traditionally, it is used to treat stomach irritation, diarrhea, and abdominal cramp. 
The recommended traditional herbs and spices are mainly for the reduction of COVID-19 symptoms such as cold, fever, impaired immunity, etc. However, the recommended herbal therapeutics/hot water extract/decoction are whether sufficient enough to alleviate the infection of coronavirus in diabetic patients because of an impaired immune-metabolism (i.e.) uncontrolled blood glucose, hyperglycemia mediated oxidative stress, impaired insulin action mediated low-grade inflammation, and poor immunity mediated cytokine storm.

Moreover, the possibility of viral survival in a hyperglycemic condition can also promote viral load in diabetic patients. This suggests that multiple drugs are needed for the treatment of diabetic patients with COVID-19. Thus, the present review has selected and reviewed different herbs and spices (Figure 2) based on their traditional medicinal values and available pharmacological activities (antiviral, antioxidant, anti-hyperglycemic, anti-inflammatory, and immunostimulant effects) for the fulfilling therapeutic needs of the infected patients with or without diabetes (Table 1).

\section{TRADITIONAL AND PHARMACOLOGICAL PROPERTIES OF HERBS-SPICES}

\subsection{Herbs and spices with antiviral property}

The anti-viral activity of plenty of medicinal plants has been well documented in India and other countries. Medicinal plants can interfere the virus growth at different stages (Akram et al., 2018). A tropical South Asian plant, Andrographis paniculata has been displayed robust antiviral potential against viral infections (Yarnell, 2017). Traditionally, it is used for the treatment of fever, sore throat, cold, cough, etc. This herb possesses various other medicinal claims such as hypoglycemic, anti-inflammatory, immune-stimulatory, antithrombotic, anticancer, and hypotensive properties (Ajaya Kumar et al., 2004)

In addition, it also reduced the symptoms of acute respiratory tract infections in adults and children ( $\mathrm{Hu}$ et al., 2017). Recently, the antiviral potential of A.paniculata and its active constituents has been discussed elaborately with the fundamental mechanisms (Jiang et al., 2021). A series of in vitro and in silico studies also confirmed the anti-dengue activity of andrographolide, an active constituent of $A$. paniculata against the dengue- 2 virus. Moreover, $A$. paniculata can repress the molecules [Caspase-1, IL-1 $\beta$, and NOD-like receptor proteins] that are associated with the pathogenesis of SARS-CoV and SARS-CoV2 (Kaushik et al., 2021; H. Liu et al., 2021). The computational study of neoandrographolide, an active compound of $A$. paniculata has been depicted potency against the SARS-CoV2 virus (Murugan et al., 2021)

Glycyrrhiza glabra is an Indian traditional medicine, which shows antimicrobial, antioxidative, immunomodulatory, antiallergic, and anti-inflammatory functions (Kwon et al., 2020) . It is also used as a sweetening and flavoring agent in beverages, toothpaste, candies, chewing gums, and tobaccos (Asada et al., 2000). The extract of $G$. glabra has been reduced allergic rhinitis in clinical trials and in vitro and in vivo experiments (Chang et al., 2021). Furthermore, the antiviral property of $G$. glabra has well been documented against various viruses such as hepatitis B, hepatitis C, SARS-related coronavirus, human immunodeficiency virus 1 (HIV-1), vesicular stomatitis virus, vaccinia virus, respiratory syncytial virus, and arboviruses (Fiore et al., 2008). Glycyrrhizic acid, a triterpene of G. glabra has the potential to inhibit the proliferation of HIV and displays immune activation (Sun et al., 2019). Moreover, the aqueous extract and the purified polysaccharides of G. glabra have been shown an anti-adhesive effect against the binding of Helicobacter pylori in the gastric mucosa of humans (Wittschier et al., 2009). In addition, the mixture of G. glabra and fermented milk containing $L$. paracasei has reduced the histological inflammation and the density of Helicobacter pylori in the infected patients (Yoon et al., 2019) . Apart from this, the active constituents of G. glabra (Glycyrrhizic acid, Liquiritigenin, and Glabridin) also displayed non-covalent interaction with the active site amino acids of SARS-CoV2 major protease, which is considered as the main drug target because this enzyme involves in the processing of poly-protein, a translated product of the SARS-CoV2 RNA. Among these compounds, glycyrrhizic acid has displayed a high binding affinity with the best ADMET (good solubility, permeation, absorption, noncarcinogenic and non-toxic) characteristics (Srivastava et al., 2020). Furthermore, it has been explained that the antioxidant and anti-inflammatory potentials of G. glabra can induce the formation of interferons in humans (Sudhakar et al., 2021). The available studies are confirming the antiviral potential and gastro-protective effect of $G$. glabra in humans.

Azadirachta indica (neem) is considered a spiritual tree in India. It is also distributed in Africa and America. It showed a wide range of therapeutic actions and receives considerable attention worldwide. All parts of this tree have been used in folk medicine to treat various complications. It shows plentiful pharmacological actions including anti-viral and anti-inflammatory properties (Ashfaq et al., 2016). The hand sanitizer prepared from the extract of $A$. indica, Ocimum sanctum, and Citrus limon showed broadspectrum antimicrobial activities as that of alcoholic hand sanitizer (Acharya et al., 2018). In North-Western Morocco; 20 different plant species are available in the herbal market to treat and prevent COVID-19 infections. Of which the most frequently used plants are Azadirachta indica A. Juss, Eucalyptus globulus, and Ziziphus lotus (L.) Lam (Chaachouay et al., 2021). In addition, the computational analysis of phytochemicals belongs to $A$. indica, O. santum, Aloe vera, Salvia officinalis, and Tinospora cordifolia revealed their potency to disturb the conserved replication domain of the RNAdependent RNA polymerase of the coronavirus (Balakrishnan et al., 2020) . The leaves phytochemicals of $A$. indica, $M$. oleifera, and Mangifera indica showed remarkable docking scores with the main protease of the SARS-CoV2 as compared to the interactions of hydroxychloroquine (Umar et al., 2021). Ocimum sanctum (Tulsi) is also a spiritual herb in India. It is the only plant, which has a wide range of nutritional and medicinal properties, therefore, it is considered as the queen of 
medicinal herbs/green medicine. The juice of tulsi leaf cures bronchitis, acute respiratory syndrome, fever, cold, and cough. Overall, tulsi has been improved the defense mechanism against viral infections in humans (Patel, 2020). Furthermore, the active constituents of tulsi such as beta-carotene, eugenol, and caryophyllene exhibit inhibitory effects against the SARS-CoV2 spike protein (facilitates virus attachment) through their strong docking score (Kar et al., 2020).

Sengupta (2020) has been explored the role of Piper betel against COVID-19 infections. The active metabolite of Piper betel, aurantiamide possesses chymotrypsin-like-proteases like activities that can inhibit the coronavirus. In addition, the other active constituents (piperol, caryophyllene, chavibetol, catechol, betlol, eugenol, etragol, quercetin, etc.) of Piper betel also developed the self-defense mechanism against the coronavirus infection. Numerous medicinal plants, including Citrus spp., inhibited the pathogenesis of COVID-19 and also relieved cough and fever in COVID-patients (Jalali et al., 2021). Moringa oleifera Lam has been traditionally used to treat HIV infection in Africa. It is also effective against various viruses (Biswas et al., 2020). Furthermore, the active compound, niaziminin, and three flavonoids (isorhamnetin, kaempferol, and apigenin) from Moringa oleifera showed the strongest interaction with the main protease of SARSCoV2 (Shaji et al., 2021).

\subsection{Anti-hyperglycemic effects of herbs and spices}

Studies on medicinal plants/herbs or spices have been elaborated about their single or multiple pharmacological effects. The polyherbal formulation of 12 different plants, including Neembark/Neem, Haridra/turmeric, Methi seeds/fenugreek seeds, Gudamar/Gymnema sylvestre, Indian blackberry seed, etc. were showed a hypoglycemic effect in T2D and suggested that this can be given as an adjuvant treatment along with the hypoglycemic agents (Khedikar \& Erande, 2018). Moreover, the compounds of common herbs and spices were screened in silico against 18 known drug targets of diabetes for the validation of their anti-hyperglycemic and anti-hyperlipidemic actions (Khedikar \& Erande, 2018). Recently, the antidiabetic activity of neem (A. indicia) leaf extract has been well documented in a randomized, double-blind, placebocontrolled clinical study (Pingali et al., 2020). This study revealed that the aqueous extract of neem leaves had significantly reduced hyperglycemia, oxidative stress, systemic inflammation, and endothelial dysfunction in type 2 diabetic subjects. The inhibitor of sucrase enzyme has been considered as an oral antidiabetic therapy, which can delay the absorption of carbohydrates, reduce the level of postprandial glucose and promote the levels of insulin to attain normoglycemia. For example, the identified active constituents of $A$. indica leaf have been depicted a remarkable inhibitory activity of sucrase, which confirms the anti-diabetic potential of $A$. indica (Abdelhady et al., 2016). Furthermore, herbs also potentiate insulin secretion from the pancreas and thereby regulate blood glucose. It is evident that the curry leaves (Murraya koenigii) activated beta-cells of the pancreas and promoted the biosynthesis of insulin ( $\mathrm{Bi}$ et al., 2017) . Apart from this, Citrus limon (lemon flavedo) extracts have been inhibited the carbohydrate hydrolyzing enzymes, and also displayed antioxidant activity (S.Y. Lu et al., 2021). Furthermore, Phyllanthus emblica/Amla/Indian gooseberry showed various pharmacological actions such as antioxidant, antidiabetic, immunomodulatory, anti-inflammatory, analgesic, antimicrobial, anti-cancer activities, etc. (Yadav et al., 2017) . The efficiency of amla for the management and prevention of T2D has been well documented. For example, the amla shows diverse mechanistic actions for the regulation of blood glucose that include beta-cell protection, enhanced insulin secretion, improved insulin signaling, and reduced insulin resistance, oxidative stress, inflammatory reactions, and advanced glycation end-products accumulation (H.Z. Huang et al., 2021).

The antidiabetic activity of cumin (Cuminum cyminum) and black pepper (Piper nigrum) has been well documented. Cumin can preserve beta cells of the pancreas, increase insulin secretion and enhance glucose storage. Moreover, the use of black pepper/piperine, an active compound of black pepper with other spices promoted the antidiabetic activity of coexisted spices (Bi et al., 2017; Pereira et al., 2019). Turmeric (Curcuma longa) performs different functions (promotes gut absorption, beta-cell functions, and improves insulin resistance) and thereby displayed antidiabetic action (Beidokhti \& Jäger, 2017). It has been regarded that the polyphenolic content of spice exerts multiple effects on glucose metabolism (glucose absorption, transport, storage, and control on hepatic glucose output), insulin release, and its receptor activation (Hanhineva et al., 2010). The available background suggests that the use of the selected herbs-spices can induce and promote the actions of insulin and carbohydrate metabolizing enzymes in diabetic subjects.

\subsection{Antioxidant and anti-inflammatory effects of herbs and spices}

The enhanced generation and accumulation of reactive oxygen species can induce the oxidative stress-mediated damage of biomolecules (protein, lipids, and nucleic acids). The oxidative damage/injury mediated inflammatory response can increase the oxygen uptake and respiratory burst of leukocytes and mast cells. This event can eventually release and accumulate ROS in the damaged area. In addition, the release of soluble inflammatory mediators (cytokines, chemokines, and arachidonic acid) from the inflammatory cells can also release more reactive species and stimulate various inflammatory transcription factors including nuclear factor kappa B (NF$\kappa \mathrm{B}$; which plays a key role in the amplification of oxidative stress-induced inflammation). Further, this can increase the expression of various inflammatory cytokines (TNF-a, IL6, IL-1b, chemokines (CXC chemokine receptor 4) and thereby exert adverse effects on normal cellular events. For example, the increased TNF-a level was directly associated with insulin resistance of obese mice (Hotamisligil et al., 1993). Moreover, the downregulation of TNF-a has been improved the phosphorylation of insulin receptor substrate-1 (IRS-1) 
in the insulin-treated HepG2 cells (Alipourfard et al., 2019). Apart from this, hyperglycemia and increased free fatty acidinduced ROS accumulation also impair insulin sensitivity in diabetes (Rains \& Jain, 2011). This infers that hyperglycemiaoxidative stress-inflammation mediated cytokine accumulation can impair normal insulin function and thereby cause insulin resistance.

In the modern world, oxidative stress (i.e. imbalance between free radicals and endogenous antioxidant system) and inflammation are considered as the major risk factors for the pathogenesis of most diseases. It is well known that plants/herbs and spices are good reservoirs of antioxidants. The inclusion of antioxidants-rich natural sources in daily food can solve health issues associated with oxidative stress. The intake of antioxidantrich natural foods has been shown an inverse relationship to human illness (Krishnaiah et al., 2011).

The antioxidant potentials of natural compounds are mainly linked to their flavonoids and polyphenolic contents. In addition, trace metals such as zinc, copper, manganese, magnesium, and selenium, and dietary vitamins (Vitamin C, $\mathrm{E}$, and carotenoids) also act as antioxidants (Arulselvan et al., 2016; Irshad \& Chaudhuri, 2002). Apart from this, dietary polyphenols and flavonoids also act as anti-inflammatory agents. For example, the extracts of natural compounds or bioactive compounds exerted their anti-inflammatory activity through the blocking of NF- $\kappa \mathrm{B}$ and mitogen-activated protein kinases signaling pathways (Arulselvan et al., 2016). Furthermore, the major active compound of $A$. Paniculata (i.e.) andrographolide has been shown a broad spectrum of pharmacological activities. For example, it inhibited oxidative stress and regulated the oxidative stress-mediated disease progression like diabetes, etc. (Dai et al., 2019). In addition, it also prevented the formation of free radicals either through its protective action of mitochondria or inhibitory action over free radicals producing enzymes. Apart from this, it also regulated the nuclear factor erythroid 2-related factor 2 (Nrf2) signaling pathway for the increased expression and activity of endogenous antioxidants (Mussard et al., 2019). Moreover, andrographolide inhibited the nuclear factor kappa $\mathrm{B}(\mathrm{NF}-\kappa \mathrm{B})$ and other transcription factors and thereby reduced the inflammation in both in vitro and in vivo (Dai et al., 2019).

Citrus limon (Lemon) has rich in vitamin $\mathrm{C}$ and minerals. Vitamin $\mathrm{C}$ is a well-known antioxidant and acted as a co-factor for various biological processes including immune potentiation and synthesis of collagen and hormone (Chambial et al., 2013). Lemon fruit juice shows acidic $\mathrm{pH} 2-3$ due to the presence of the increased quantity of ascorbic acid and citric acid. Therefore, it is considered as an efficient and eco-friendly acid catalyst in various organic transformations such as C-heteroatom and C$\mathrm{C}$ bond generating reactions (Das, 2020). In addition, lemon shows several therapeutic actions such as anti-inflammatory, antiparasitic, antimicrobial, and anticancer activity (KlimekSzczykutowicz et al., 2020). The inhalation aromatherapy using lemon also reduced the several abnormalities in acute myocardial infarction patients (Rambod et al., 2020).
The extract of amla/Indian gooseberry/Phyllanthus emblica has been altered the inflammatory and immunological processes for the healing of damaged areas (M.K. Singh et al., 2015). The extract of amla also inhibited the activation of NF-kB, a key regulator for the release of inflammatory and proinflammatory cytokines (Kim et al., 2010) . This suggests that the intake of amla can reduce the amplification of proinflammatory cytokines in inflammatory diseases. In addition to this, (Lakshmi et al., 2020) has been explained that the ingredients of Nelllikkai Legiyam (alkaloids, polysaccharides, lectins, glycosides, phenolic compounds, flavonoids, tannins, and saponins) depicted various pharmacological activities such as antioxidant, anti-inflammatory, immunomodulatory, antiasthmatic, anti-microbial and anti-cancerous activity. Moreover, the curry leaf has been used in folk medicine for the treatment of inflammation, renal problems, vomiting, and diabetes (Ganesan et al., 2013) .

The active compounds of turmeric, especially curcumin showed remarkable antioxidant and immunomodulatory properties (S.C. Gupta et al., 2013). The consumption of Curcuma longa Linn. (Curcumin) with milk has been blocked the release of pro-inflammatory cytokines, especially IL-1, IL-6, and TNF-alpha (Omar et al., 2010). Recently, it has been documented that either extract, powder, or isolated bioactive compounds of ginger (Zingiber officinale) and turmeric ( $C$. longa) are showed anti-inflammatory action and thereby cured inflammation (Azeez \& Lunghar, 2021). As per the metaanalysis data, ginger did not alter the concentrations of IL6 and soluble intercellular adhesion molecules. But the supplementation of ginger reduced the blood levels of Creactive protein, high sensitivity C-reactive protein, and TNF- $\alpha$ significantly in a randomized controlled trial (Morvaridzadeh et al., 2020). Apart from this, the antioxidant and anticoagulation properties of ginger are also well studied. Moreover, ginger also reduces vomiting, pain, and controls nausea (Arablou \& Aryaeian, 2018). Thus, the intake of multi-bioactive antioxidants (polyphenols, flavonoids, trace metals, and vitamins) enriched herbs, and spices can ameliorate chronic inflammation and impaired insulin sensitivity in COVID-19 people with or without co-morbidities like diabetes, etc. Furthermore, the herbal-spices active compounds could serve as non-steroidal anti-inflammatory agents. The discovery of natural steroids like anti-inflammatory compounds from the suggested source could protect people from the deleterious side effects of steroids therapy.

\subsection{Immunomodulatory effects of herbs and spices}

The immunomodulators are either dietary supplements, a group of medicines, or compounds of herbs-spices that can increase immunity through the increased assembly of immunestimulating molecules like interferons, etc. The different immunomodulation studies including experimental and clinical trials have been revealed that the immunomodulators like herbal plants and their components have improved the impaired immunity of individuals with diabetes, HIV, rheumatoid 
arthritis, etc., (Malagi, 2018). The medicinal plants and herbal compounds have been upregulated the functions and non-specific immunomodulation of immune cells connected to natural immunity such as granulocytes, natural killer cells (NK cells), and macrophages. For example, the natural compounds are stimulated macrophages and lymphocytes ( $T$ and $B$ ) for the secretion of cytokines, and antibodies and thereby cause refined switching (Tie et al., 2016). In addition, the ingested natural polyphenols triggered the immunity against viruses through the activation of the innate immunity signaling cascade, in addition to their other biological activities (Nieman \& Wentz, 2019)

These compounds are largely present in plants either in the form of glucose esters or aglycones (Ma et al., 2014). For example, curcumin and epigallocatechin gallate cause epigenetic alterations within cells and also control allergic responses in the gastrointestinal tract (Ding et al., 2018).

The viral infection can cause hypovitaminosis and also reduces the levels of essential minerals such as zinc, copper, and magnesium. Zinc is an important mineral that regulates immunity against viral infections. For example, zinc-deficient people are more prone or highly susceptible to microbial infections, especially viral infections (Read et al., 2019). Apart from this, the supplementation of zinc also reduced the pneumonia symptoms in the infected children when compared to control in terms of rate of respiration, oxygen saturation, and duration of illness (Acevedo-Murillo et al., 2019). Copper also plays a major role in the development and differentiation of immune cells (C. Li et al., 2019). Furthermore, copper chelates of a natural monoterpenoid (thujaplicin) reduced the influenza virus multiplications in humans (Rupp et al., 2017). Moreover, the imperative role of magnesium is also reported in the infected cells. This vital mineral regulates the functions of various immune cells, such as macrophages, $T$ lymphocytes, $\mathrm{B}$ lymphocytes, and helper cells (Liang et al., 2012).

Vitamins function as antioxidants and regulate various nutrient metabolisms (Falowo et al., 2018). Moreover, vitamin $\mathrm{C}$ exerts multiple effects on innate immunity and adaptive immunity. It stimulates immune cell functions (neutrophils and macrophages) for effective killing and elimination of microbes. Vitamin C protected the host cells by increasing apoptosis, decreasing neutrophil necrosis, and NETosis, and clearing excessive neutrophils. Furthermore, it also promoted the functions of various immune cells and thereby prevented respiratory and systemic infections (Carr \& Maggini, 2017). Recently, it has been stated that a high-dose intravenous vitamin $\mathrm{C}$ can suppress acute respiratory distress syndrome, reduce cytokine storms and improve pulmonary function in patients with the COVID-19 (F. Liu et al., 2020). Vitamin $\mathrm{E}$ is a lipid-soluble antioxidant. The dietary vitamin $\mathrm{E}$ regulated various immune cell functions and promoted humoral and cell-mediated immunity in humans and animals. For example, it increased the proliferation and functions of $\mathrm{B}$ and $T$ lymphocytes in humans and animals (Lee \& Han, 2018). Apart from this, vitamin A also showed antiinflammatory and immune-boosting functions (Z. Huang et al., 2018). This confirms that viral infection must be treated with therapeutics/immunomodulators with the summation of essential vitamins (A, D, C, E, and $\mathrm{K}$ ) and minerals to establish proper immune functions against viral infection (Gunville et al., 2013). By considering the roles of multiple vitamins and minerals in the development of immunity, the current review has discussed the possible contributions of herbs-spices for the boosting up of the impaired immunity under viral infections, like COVID-19.

The leaves of $M$. oleifera are used like spinach in India. The dried and powdered forms of the leaf are used in the preparation of soups and sauces. It is considered as the most important medicinal plant and functional food. All parts of the tree have been used traditionally for various common ailments including, anemia, respiratory disorders, diarrhea, cholera, headaches, sore throat, chest congestion, diabetes, etc. The aqueous leaf extract of $M$. oleifera contains numerous bioactive secondary metabolites such as kaempferol, quercetin, vanillin, ferulic acid, ellagic acid, gallic acid, and chlorogenic acid (B.N. Singh et al., 2009). The leaf of $M$. oleifera is also considered as the best source of vitamins such as vitamin $\mathrm{C}$, vitamin $\mathrm{A}$, vitamin $\mathrm{E}, \mathrm{B}$ vitamins (thiamine, riboflavin, and niacin) and minerals when compared to other food products (Falowo et al., 2018; Leone et al., 2015). The multi-vitamins enriched $M$. oleifera leaf depicted the immunomodulatory potential and antiherpetic actions in different studies (Kurokawa et al., 2016; Rachmawati, 2014). In addition, it also showed various pharmacological attributes such as antioxidant, anti-inflammatory, analgesic, antihypertensive, diuretic, and antidiabetic activities (Padayachee \& Baijnath, 2020; Rachmawati, 2014).

The immunostimulant property of Andrographis paniculata has been well-established in addition to its antiviral property (Churiyah et al., 2015). The hot water extract of A. paniculata is called "nilavembu kudineer" in the Tamil language. It showed remarkable immunomodulatory activity against various viral diseases (AlaguLakshmi et al., 2020). It also has the potential to block the entry and pathogenesis of coronavirus through its action against the ACE 2 receptor or its immunomodulatory activity (Walter et al., 2020).

Moreover, the therapeutic, healing and nutritional potentials of Indian gooseberry or its tonic can build up lost vitality and vigor. It is enriched with numerous phytoconstituents (polyphenols, flavonoids, tannins), vitamins, minerals, etc., (Variya et al., 2016). Apart from this, the vitamin $\mathrm{C}$ content of amla has been increased the proliferation and activity of splenic natural killer (NK) cells in two-folds and also increased the life of mice with tumors (Suresh \& Vasudevan, 1994). Furthermore, the administration of amla extract has been increased the leukocyte count, lymphocyte distribution, antibody titer, and delayed hypersensitivity in the mice (Suja et al., 2009). This demonstrates that amla can stimulate humoral immunity and cell-mediated immunity. Recently, the immunomodulatory effects of Phyllanthus species, including P. emblica have been documented without validation (Jantan et al., 2019). Apart from this, the herbal formulation 
(KM1608) of three medicinal plants (Z. officinale, Saussurea lappa, and Terminalia chebula) also displayed an enhanced immune response in RAW 264.7 macrophages (Trinh et al., 2020).

Papaver somniferum L (Poppy seeds) is considered as one of the tasty food ingredients and also a major source of active compounds. Traditionally, it is used as an analgesic. And also reduces fever, thirst, inflammation, stomach irritation, diarrhea, and abdominal cramp. It contains a large amount of alpha-linolenic acid and tocols (tocopherols and tocotrienols) (Bozan $\&$ Temelli, 2008). It also contains various minerals such as copper, magnesium, zinc, iron, manganese, and phosphorus. It showed antioxidant and various proteinase inhibitory activities (Kroslak et al., 2017). Furthermore, each poppy seed contains an enormous quantity of zinc, therefore it is believed that it can stimulate the production of white blood cells and increase immunity against foreign agents (Rink \& Gabriel, 2000). Another important mineral of poppy seed is iron. It is well known that iron is essential to RBCs for the transportation of oxygen from the lungs to all cells. Thus, it normalizes the anemic level and also increases blood flow, and thereby oxygenates vital parts of the body (Keel et al., 2008). As it contains a higher fiber quantity, it can control diarrhea and regulates the normal peristaltic movement in the intestine (Callaway, 2004). In addition, the presence of both fiber and zinc contents in poppy seeds has been shown protection against diabetes (Lachman et al., 2006).

The discussed traditional and pharmacological benefits of the selected 14 herbs-spices reveal that the formulation and use of these herbs-spices mixtures can potentially eradicate the coronavirus infection and its pathogenesis in humans with or without any comorbidity like diabetes, etc. Generally, the available dosage forms of the processed herbs and plants include whole herb, decoctions, herbal teas, syrup, capsules, etc. For the preparation of decoctions, herbs/plant materials are boiled in water to extract the active constituents. The water decoction of a mixture of 2-12 herbal materials has been considered the commonest traditional herbal dosage (Parasuraman et al., 2014; Yi \& Chang, 2004). Therefore, this review recommends that the powdered form of the selected herbs-spices can be prepared and mixed at particular ratios based on their recommended intake and stored in an airtight container. Further, the preparation of decoction (i.e.) hot water extract of the herbs-spices mixture could be enriched with multiple phytotherapeutics, essential vitamins, and minerals. These bioactive compounds could act collectively and thereby exert multiple therapeutic effects (antiviral, anti-diabetic, antioxidant, anti-inflammatory, and immunomodulatory activities) at the level of entry and modes of the pathogenesis of the coronavirus (Scheme 1).

The enriched anti-viral compounds could interact with the spike protein of the virus and angiotensin-converting enzyme 2 (ACE2) receptor of the host and thereby hinder the entry of coronavirus. The anti-inflammatory compounds of the herbsspices mixture could alleviate the coronavirus infection-induced undesirable immunological response mediated cytokine storm, clot formation, and fluid accumulation in the alveoli. The antiviral and anti-inflammatory actions of herbs-spices could destroy the coronavirus and normalize the pulmonary defects and associated respiratory problems in the infected individuals. Furthermore, the polyphenols and flavonoids of the herbsspices mixture could protect the pancreatic beta-cells and normalize the defected insulin signaling and unregulated hyperglycemia. In addition, the antioxidants, anti-inflammatory, and immunomodulatory compounds of herbs-spices could mitigate the hyperglycemia-induced oxidative stress and associated inflammatory pathway activation mediated cytokine storm and eventual multi-organ failure in the infected diabetic individuals (Scheme 1).

\section{CONCLUSION}

The current scenario of the COVID-19 pandemic infers that vaccination is the only solution for the saving of people's life. Because the vaccination may offer certain kinds of protection against the infection of the novel coronavirus 19 . However, the emergence of mutated strains of the coronavirus and its massive infection-mediated mortality among individuals with or without any comorbidity are increased in the second wave, especially in India and other countries. Globally, more than $70-80 \%$ of people are vaccinated. However, coronavirus-infected cases have been reported still. It raises the question about the efficiency of vaccines against the variants of coronavirus. The $\mathrm{WHO}$ also suggested that the efficacy of vaccines must be examined among the vaccinated and non-vaccinated population to validate the impacts of vaccines on the mutants of the coronavirus. Furthermore, the available therapeutics against the coronavirus, especially steroids therapy have been causing numerous side-effects such as pneumonia, diabetogenic effect/uncontrolled hyperglycemia, reduced immunity mediated mucormycosis, and clotting mediated sudden death in infected individuals with or without any other comorbidities, especially in diabetic subjects. Thus, still, there is a need for effective vaccine(s) and antiviral drug(s) with multiple actions to overcome the deleterious impacts of the coronavirus infection. It is well known that "the protection is better than cure". Thus, this review has detailed the traditional and pharmacological benefits of 14 herbs-spices. Also, the intake of the suggested herbal-spices mixture in the form of either hot water extract/decoction/tea or dietary inclusion could protect people from the infection of the novel coronavirus 19 and its emerging variants. As this approach involves eco-friendly phytotherapeutics, it would not cause any undesirable side effects to the infected or uninfected people. Furthermore, this herbal-spices mixture could efficiently act against the coronavirus infection through its multiple therapeutic effects like pancreas protection, improving defected insulin signaling, maintaining normal glycemic index, reducing inflammation and establishing anti-inflammatory signals, promoting immunity, and abolishing cytokine storm mediated pulmonary trouble and multiorgan failure. Though the herbs and spices exert therapeutic and prophylactic effects, 


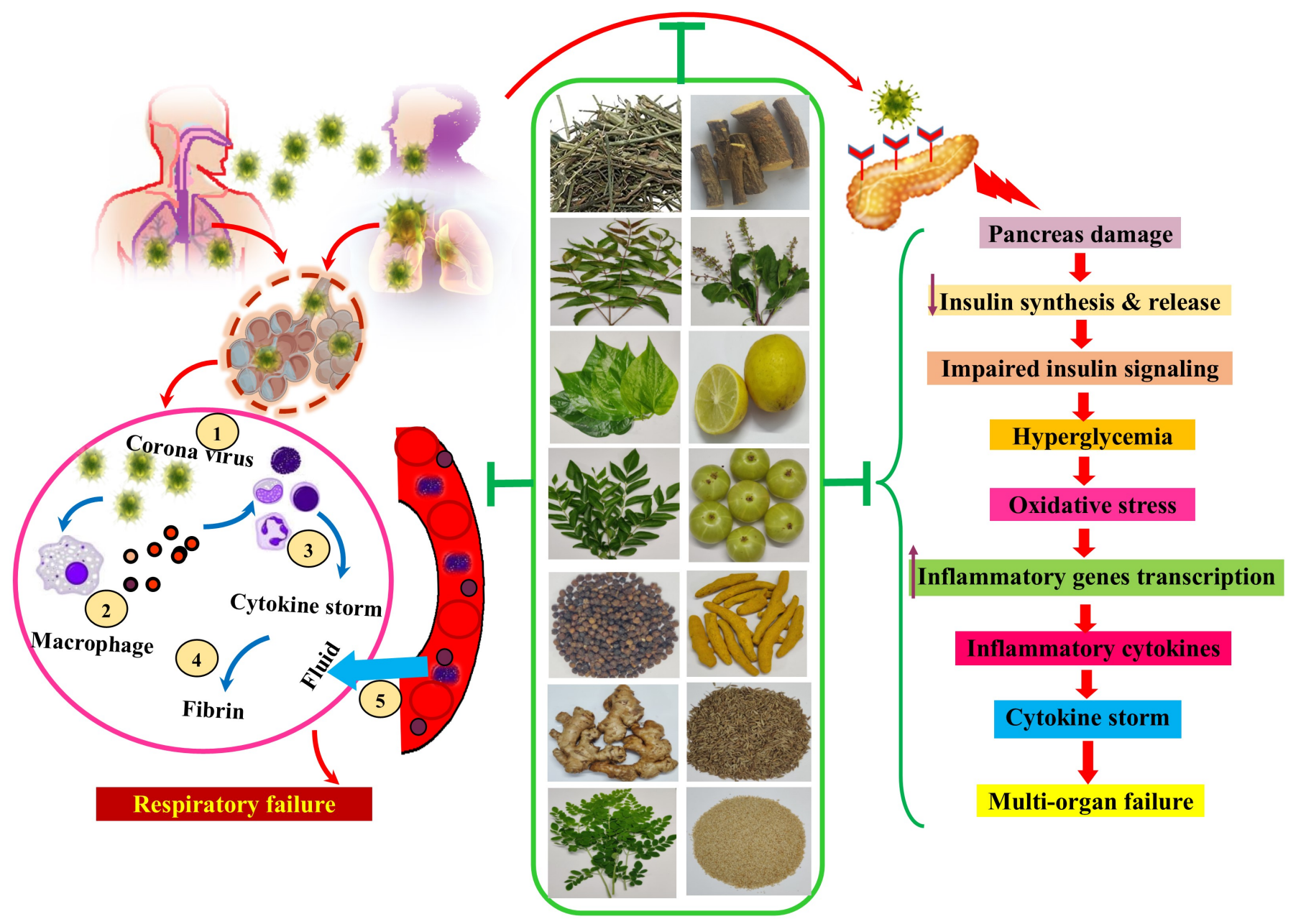

Scheme 1. The multiple therapeutic effects of the herbs-spices mixture against the coronavirus infection and its pathogenesis in diabetic individuals. The selected herbs-spices mixture possibly act against the coronavirus infection in different modes of actions such as anti-viral, anti-diabetic, antioxidant, anti-inflammatory, and immunomodulatory actions. 1 - Coronavirus entry into alveoli; 2- response of immune cells (immunity) and inflammation-mediated recruitment of immune cells; 3 - cytokine storm; 4 - fibrin clot formation; 5 - blood vessel permeability mediated fluid accumulation in the alveoli.

the sequence of in vitro and in vivo studies and clinical trials must be carried out for the proper validation of its efficacy and mode of action against the coronavirus.

\section{ABBREVIATIONS}

ACE2, angiotensin-converting enzyme 2; AMPK adenosine monophosphate-activated protein kinase; ADMET, absorption, distribution, metabolism, excretion, and toxicity; AYUSH, ayurvedic-yoga and naturopathy-unani-siddha and homeopathy; CD cells - cluster of differentiation cells; COVID-19, coronavirus disease 2019; HbA1C, glycated hemoglobin; HIV-1, human immunodeficiency virus-1; ICU intensive care unit; IDF, international diabetes federation; IFN$\gamma$, interferon-gamma; IL-6, interleukin 6; IL-12, interleukin 12; IRS-1, insulin receptor substrate-1; MERS, middle east respiratory syndrome; NF-Kb, nuclear factor kappa light chain enhancer of activated B cells; Nrf2, nuclear factor erythroid 2-related factor 2; NK cells, natural killer cells; NF- $\kappa \mathrm{B}$, nuclear factor kappa B; PBMC, peripheral blood mononuclear cell; PMNs, poly morpho-nuclear cells; RAW 264.7, Ralph and William's cell line 264.7; SARS-CoV, severe acute respiratory syndrome - coronavirus; $\mathrm{T}$ and $\mathrm{B}$ cells, Thymus and bonemarrow/ bursa derived cells; T1D, type1 diabetes; T2D, type 2 diabetes; TCM, traditional Chinese medicine; TNF- $\alpha$, tumor necrosis factor-alpha; WHO, World health organization.

\section{CONFLICTS OF INTEREST}

The authors declare no competing of interest.

\section{ACKNOWLEDGMENTS}

The authors wish to thank the All India Council for Technical Education (AICTE), New Delhi, India, for utilizing the research facility established under the Research Promotion Scheme (Ref. No: 8-164/RIFD/RPS/POLICY-4/2013-140. 
ORCID

$\begin{array}{ll}\text { Rajasekar Panchamoorthy } & 0000-0002-1385-5265 \\ \text { Nethra Vel } & 0000-0001-6827-6474\end{array}$

\section{AUTHOR CONTRIBUTIONS}

RP - Research concept and design; RP, NV - Collection and/or assembly of data; RP - Data analysis and interpretation; $\mathrm{RP}, \mathrm{NV}$ - Writing the article; RP - Critical revision of the article; RP, NV - Final approval of the article. .

\section{REFERENCES}

Aara, A., Chappidi, V., Ramadas, M., 2020. Antioxidant activity of eugenol in Piper betel leaf extract. Journal of Family Medicine and Primary Care. 9, 327-331. https://doi.org/10.4103/jfmpc.jfmpc _809_19

Abdelhady, M.I.S., Shaheen, U., Bader, A., Youns, M.A., 2016. A new sucrase enzyme inhibitor from Azadirachta indica. Pharmacognosy Magazine. 12, 293-296. https://doi.org/10.4103/0973-1296 .185705

Acevedo-Murillo, J.A., León, M.L.G., Firo-Reyes, V., SantiagoCordova, J.L., Gonzalez-Rodriguez, A.P., Wong-Chew, R.M., 2019. Zinc supplementation promotes a Th1 response and improves clinical symptoms in fewer hours in children with pneumonia younger than 5 years old. A randomized controlled clinical trial. Frontiers in Pediatrics. 7, 431. https://doi.org/10.3389/fped.2019.00431

Acharya, S.B., Ghosh, Saradindu, Yadav, G., Sharma, K., Ghosh, Sirsendu, Joshi, S., 2018. Formulation, evaluation and antibacterial efficiency of water-based herbal hand sanitizer gel. bioRxiv, 373928. https:// doi.org/10.1101/373928 https://doi.org/10.1101/373928

Ajaya Kumar, R., Sridevi, K., Vijaya Kumar, N., Nanduri, S., Rajagopal, S., 2004. Anticancer and immunostimulatory compounds from Andrographis paniculata. Journal of Ethnopharmacology. 92, 291-295. https://doi.org/10.1016/J.JEP.2004.03.004

Akram, M., Tahir, I.M., Shah, S.M.A., Mahmood, Z., Altaf, A., Ahmad, K., Munir, N., Daniyal, M., Nasir, S., Mehboob, H., 2018. Antiviral potential of medicinal plants against HIV, HSV, influenza, hepatitis, and coxsackievirus: A systematic review. Phytotherapy Research. 32, 811-822. https://doi.org/10.1002/ptr.6024

AlaguLakshmi, S., Shafreen, R.M.B., Priya, A., Shunmugiah, K.P., K., 2020. Ethnomedicines of Indian origin for combating COVID19 infection by hampering the viral replication: using structurebased drug discovery approach. Journal of Biomolecular Structure and Dynamics. 2, 1-16. https://doi.org/10.1080/07391102.2020 .1778537

Alipourfard, I., Datukishvili, N., Mikeladze, D., 2019. TNF- $\alpha$ downregulation modifies insulin receptor substrate 1 (IRS-1) in metabolic signaling of diabetic insulin-resistant hepatocytes. Mediators of Inflammation. 2019, 3560819. https://doi.org/10.1155/2019/ 3560819

Arablou, T., Aryaeian, N., 2018. The effect of ginger (Zingiber officinale) as an ancient medicinal plant on improving blood lipids. Journal of Herbal Medicine. 12, 11-15. https://doi.org/10.1016/j.hermed.2017 .09 .005

Arulselvan, P., Fard, M.T., Tan, W.S., Gothai, S., Fakurazi, S., Norhaizan, M.E., Kumar, S.S., 2016. Role of antioxidants and natural products in inflammation. Oxidative Medicine and Cellular Longevity. 2016, 5276130. https://doi.org/10.1155/2016/5276130

Asada, Y., Li, W., Yoshikawa, T., 2000. Biosynthesis of the dimethylallyl moiety of glabrol in Glycyrrhiza glabra hairy root cultures via a non- mevalonate pathway. Phytochemistry. 55, 323-326. https://doi.org/ 10.1016/s0031-9422(00)00327-7

Ashfaq, U.A., Jalil, A., Qamar, M.T., 2016. Antiviral phytochemicals identification from Azadirachta indica leaves against HCV NS3 protease: an in silico approach. Natural Product Research. 30, 18661869. https://doi.org/10.1080/14786419.2015.1075527

Azeez, T.B., Lunghar, J., 2021. Anti-inflammatory effects of turmeric (Curcuma longa) and ginger (Zingiber officinale). Inflammation and Natural Products, 127-146. https://doi.org/10.1016/B978-0-12 $-819218-4.00011-0$

Baell, J.B., 2016. Feeling Nature's PAINS: Natural products, natural product drugs, and pan assay interference compounds (PAINS). Journal of Natural Products. 79(3), 616-628. https://doi.org/10 .1021/acs.jnatprod.5b00947

Balakrishnan, R., Vijayraja, D., Jo, S.H., Ganesan, P., Su-Kim, I., Choi, D.K., 2020. Antioxidants medicinal profile, phytochemistry, and pharmacological activities of Murraya koenigii and its primary bioactive compounds. Antioxidants. 9(2), 101. https://doi.org/10 .3390/antiox9020101

Bangash, M.N., Patel, J., Parekh, D., 2020. COVID-19 and the liver: little cause for concern. The Lancet Gastroenterology and Hepatology. 5(6), 529-530. https://doi.org/10.1016/s2468-1253(20)30084-4

Beidokhti, M.N., Jäger, A.K., 2017. Review of antidiabetic fruits, vegetables, beverages, oils and spices commonly consumed in the diet. Journal of Ethnopharmacology. 201, 26-41. https://doi.org/10.1016/ j.jep.2017.02.031

Berbudi, A., Rahmadika, N., Tjahjadi, A.I., Ruslami, R., 2019. Type 2 Diabetes and its impact on the immune system. Current Diabetes Reviews. 16, 442-449. https://doi.org/10.2174/ 1573399815666191024085838

Bhagyasri, Y., Priyanka, S., Vadithya, S., Subramanian, S., 2018. Formulation and evaluation of polyherbal syrup for antidiabetic syrup. International Journal of Pharmacy and Pharmaceutical Sciences. 3, 223-227.

Bi, X., Lim, J., Henry, C.J., 2017. Spices in the management of diabetes mellitus. Food Chemistry. 217, 281-293. https://doi.org/10.1016/ j.foodchem.2016.08.111

Biswas, D., Nandy, S., Mukherjee, A., Pandey, D.K., Dey, A., 2020. Moringa oleifera Lam. and derived phytochemicals as promising antiviral agents: A review. South African Journal of Botany. 129, 272282. https://doi.org/10.1016/j.sajb.2019.07.049

Bonaventura, P., Benedetti, G., Albarède, F., Miossec, P., 2005. Zinc and its role in immunity and inflammation. Autoimmunity Reviews. 14(4), 277-285. https://doi.org/10.1016/j.autrev.2014.11.008

Bornstein, S.R., Rubino, F., Khunti, K., Mingrone, G., Hopkins, D., Birkenfeld, A.L., Boehm, B., Amiel, S., Holt, R.I., Skyler, J.S., Devries, J.H., Renard, E., Eckel, R.H., Zimmet, P., Alberti, K.G., Vidal, J., Geloneze, B., Chan, J.C., Ji, L., Ludwig, B., 2020. Practical recommendations for the management of diabetes in patients with COVID-19. The Lancet Diabetes and Endocrinology. 8, 546-550. https://doi.org/10.1016/S2213-8587(20)30152-2

Bozan, B., Temelli, F., 2008. Chemical composition and oxidative stability of flax, safflower and poppy seed and seed oils. Bioresource Technology. 99, 6354-6359. https://doi.org/10.1016/ j.biortech.2007.12.009

Bui, T.T., Fan, Y., Piao, C.H., Nguyen, T.V., Shin, D.U., Jung, S.Y., Hyeon, E., Song, C.H., Lee, S.Y., Shin, H.S., Chai, O.H., 2020. Piper Nigrum extract improves OVA-induced nasal epithelial barrier dysfunction via activating $\mathrm{Nrf} 2 / \mathrm{HO}-1$ signaling. Cellular Immunology. 351. https://doi.org/10.1016/j.cellimm.2019.104035

Callaway, J.C., 2004. Hempseed as a nutritional resource: An overview. Euphytica. 140, 65-72. https://doi.org/10.1007/s10681-004-4811 
$-6$

Carboni, E., Carta, A.R., Carboni, E., 2020. Can pioglitazone be potentially useful therapeutically in treating patients with COVID19? Medical Hypotheses. 140, 109776. https://doi.org/10.1016/ j.mehy.2020.109776

Carr, A.C., Maggini, S., 2017. Vitamin C and immune function. Nutrients. 9(11), 1211-1211. https://doi.org/10.3390/nu9111211

Chaachouay, N., Douira, A., Zidane, L., 2021. COVID-19, prevention and treatment with herbal medicine in the herbal markets of salé prefecture. European Journal of Integrative Medicine. 42, 101285. https://doi.org/10.1016/j.eujim.2021.101285

Chamberlain, J.J., Rhinehart, A.S., Shaefer, C., Neuman, A., 2016. Diagnosis and management of diabetes: synopsis of the 2016 American diabetes association standards of medical care in diabetes. Annals of Internal Medicine. 164(8). https://doi.org/10.7326/m15 $-3016$

Chambial, S., Dwivedi, S., Shukla, K.K., John, P.J., Sharma, P., 2013. Vitamin $C$ in disease prevention and cure: An overview. Indian Journal of Clinical Biochemistry. 28(4), 314-328. https://doi.org/ 10.1007/s12291-013-0375-3

Chang, G.H., Lin, Y.S., Hsu, K.H., Cheng, Y.C., Yang, P.R., Tsai, M.S., Tsai, Y.T., Hsu, C.M., Chang, P.J., Shi, C.S., Yang, Y.H., Wu, C.Y., 2021. Nasal irrigation with Glycyrrhiza glabra extract for treatment of allergic rhinitis - A study of in vitro. Journal of Ethnopharmacology. 275, 114116. https://doi.org/10.1016/j.jep.2021.114116

Chen, N., Zhou, M., Dong, X., Qu, J., Gong, F., Han, Y., Qiu, Y., Wang, J., Liu, Y., Wei, Y., Xia, J., Yu, T., Zhang, X., Zhang, L., 2020. Epidemiological and clinical characteristics of 99 cases of 2019 novel coronavirus pneumonia in Wuhan, China: a descriptive study. The Lancet. 395, 30211-30218. https://doi.org/10.1016/ s0140-6736(20)30211-7

Chen, Y., Yang, D., Cheng, B., Chen, J., Peng, A., Yang, C., Liu, C., Xiong, M., Deng, A., Zhang, Y., Zheng, L., Huang, K., 2020. Clinical characteristics and outcomes of patients with diabetes and COVID-19 in associating with glucose-lowering medication. Diabetes Care. 43, 1399-1407. https://doi.org/10.2337/dc20-0660

Cho, N.H., Shaw, J.E., Karuranga, S., Huang, Y., Fernandes, J.D.D.R., Ohlrogge, A.W., Malanda, B., 2018. IDF Diabetes Atlas: Global estimates of diabetes prevalence for 2017 and projections for 2045. Diabetes Research and Clinical Practice. 138, 271-281. https://doi .org/10.1016/j.diabres.2018.02.023

Churiyah, P., Rofaani, O.B., Tarwadi, E., 2015. Antiviral and immunostimulant Activities of Andrographis paniculata. HAYATI Journal of Biosciences. 22(2), 67-72. https://doi.org/10.4308/hjb.22 .2 .67

Cruz, K.J.C., Oliveira, A.R.S.D., Morais, J.B.S., Severo, J.S., Mendes, P.M.V., Melo, S.R.D.S., Sousa, G.S.D., Marreiro, D.D.N., 2018. Zinc and Insulin Resistance: Biochemical and Molecular Aspects. Biological Trace Element Research. 186(2), 407-412. https://doi.org/10.1007/s12011-018-1308-z

Dai, Y., Chen, S.R., Chai, L., Zhao, J., Wang, Y., Wang, Y., 2019. Overview of pharmacological activities of Andrographis paniculata and its major compound andrographolide. Critical Reviews in Food Science and Nutrition. 59, 17-29. https://doi.org/10.1080/ 10408398.2018.1501657

Das, D., 2020. Lemon juice mediated efficient and eco-friendly organic transformations. Tetrahedron Letters. 61, 152298. https://doi.org/ 10.1016/j.tetlet.2020.152298

de Frel, D.L., Atsma, D.E., Pijl, H., Seidell, J.C., Leenen, P.J.M., Dik, W.A., Van Rossum, E.F.C., 2020. The impact of obesity and lifestyle on the immune system and susceptibility to infections such as COVID-19. Frontiers in Nutrition. 7, 597600. https://doi.org/ 10.3389/fnut.2020.597600

Defronzo, R.A., 2009. Banting Lecture. From the triumvirate to the ominous octet: a new paradigm for the treatment of type 2 diabetes mellitus. Diabetes. 58(4), 773-95. https://doi.org/10.2337/db09 $-9028$

Ding, S., Jiang, H., Fang, J., 2018. Regulation of immune function by polyphenols. Journal of Immunology Research. 2018, 1264074. https://doi.org/10.1155/2018/1264074

Driggin, E., Madhavan, M.V., Bikdeli, B., Chuich, T., Laracy, J., Biondi-Zoccai, G., Brown, T.S., Nigoghossian, C.D., Zidar, D.A., Haythe, J., Brodie, D., Beckman, J.A., Kirtane, A.J., Stone, G.W., Krumholz, H.M., Parikh, S.A., 2020. Cardiovascular considerations for patients, health care workers, and health systems during the COVID-19 pandemic. Journal of the American College of Cardiology. 75(18), 2352-2371. https://doi.org/10.1016/j.jacc.2020 .03 .031

Eckel, R.H., Grundy, S.M., Zimmet, P.Z., 2005. The metabolic syndrome. Lancet. 365, 1415-1428. https://doi.org/10.1016/s0140 $-6736(05) 66378-7$

Falowo, A.B., Mukumbo, F.E., Idamokoro, E.M., Lorenzo, J.M., Afolayan, A.J., Muchenje, V., 2018. Multi-functional application of Moringa oleifera Lam. in nutrition and animal food products: A review. Food Research International. 106, 317-334. https://doi.org/ 10.1016/j.foodres.2017.12.079

Fan, Y., Zhao, K., Shi, Z.L., Zhou, P., 2019. Bat Coronaviruses in China. Viruses. 11(3), 210. https://doi.org/10.3390/v11030210

Fiore, C., Eisenhut, M., Krausse, R., Ragazzi, E., Pellati, D., Armanini, D., Bielenberg, J., 2008. Antiviral effects of Glycyrrhiza species. Phytotherapy Research. 22(2), 141-148. https://doi.org/10.1002/ptr .2295

Frykberg, R.G., Banks, J., 2015. Challenges in the treatment of chronic wounds. Advances in Wound Care. 4, 560-582. https://doi.org/10 $.1089 /$ wound.2015.0635

Ganesan, P., Phaiphan, A., Murugan, Y., Baharin, B.S., 2013. Comparative study of bioactive compounds in curry and coriander leaves: An update. Journal of Chemical and Pharmaceutical Research. 5, 590-594.

Geerlings, S.E., Hoepelman, A.I.M., 1999. Immune dysfunction in patients with diabetes mellitus (DM). FEMS Immunology and Medical Microbiology. 26(3-4), 259-265. https://doi.org/10.1111/ j.1574-695x.1999.tb01397.x

Ghorbani, A., 2013. Best herbs for managing diabetes: A review of clinical studies. Brazilian Journal of Pharmaceutical Sciences. 49(3), 413-422. https://doi.org/10.1590/S1984-82502013000300003

Gorbalenya, A.E., Baker, S.C., Baric, R.S., Groot, R.J.D., Drosten, C., Gulyaeva, A.A., Haagmans, B.L., Lauber, C., Leontovich, A.M., Neuman, B.W., Penzar, D., Perlman, S., Poon, L.L., Samborskiy, D.V., Sidorov, I.A., Sola, I., Ziebuhr, J., 2020. The species Severe acute respiratory syndrome-related coronavirus: classifying 2019-nCoV and naming it SARS-CoV-2. Nature Microbiology. 5(4), 536-544. https://doi.org/10.1038/s41564-020-0695-z

Guan, W., Liang, W., Zhao, Y., 2020. Comorbidity and its impact on 1590 patients with Covid-19 in China: a national wide analysis. European Respiratory Journal. 55, 2000547. https://doi.org/ 10.1183/13993003.00547-2020

Gunville, C., Mourani, P., Ginde, A., 2013. The role of vitamin $\mathrm{d}$ in prevention and treatment of infection. Inflammation and Allergy Drug Targets. 12, 239-245. https://doi.org/10.2174/ 18715281113129990046

Guo, W., Li, M., Dong, Y., Zhou, H., Zhang, Z., Tian, C., Qin, R., Wang, H., Shen, Y., Du, K., Zhao, L., Fan, H., Luo, S., Hu, D., 2020. Diabetes is a risk factor for the progression and prognosis 
of COVID-19. Diabetes/Metabolism Research and Reviews. e3319, e3319. https://doi.org/10.1002/dmrr.3319

Gupta, Ghosh, A., Singh, A.K., Misra, A., 2020. Clinical considerations for patients with diabetes in times of COVID-19 epidemic. Diabetes and Metabolic Syndrome. 14(3), 211-212. https://doi.org/10.1016/ j.dsx.2020.03.002

Gupta, M., 2010. Pharmacological properties and traditional therapeutic uses of important Indian spices: A review. International Journal of Food Properties. 13, 1092-1116. https://doi.org/10.1080/ 10942910902963271

Gupta, S.C., Sung, B., Kim, J.H., Prasad, S., Li, S., Aggarwal, B.B., 2013. Multitargeting by turmeric, the golden spice: From kitchen to clinic. Molecular Nutrition and Food Research. 57, 1510-1528. https://doi.org/https://doi.org/10.1002/mnfr.201100741

Hanhineva, K., Törrönen, R., Bondia-Pons, I., Pekkinen, J., Kolehmainen, M., Mykkänen, H., Poutanen, K., 2010. Impact of dietary polyphenols on carbohydrate metabolism. International Journal of Molecular Sciences. 11(4), 1365-1402. https://doi.org/10.3390/ijms11041365

Haridas, M., Sasidhar, V., Nath, P., Abhithaj, J., Sabu, A., Rammanohar, P., 2021. Compounds of Citrus medica and Zingiber officinale for COVID-19 inhibition: In silico evidence for cues from Ayurveda. Future Journal of Pharmaceutical Sciences. 7(1), 13. https://doi.org/10.1186/s43094-020-00171-6

Hotamisligil, G.S., Shargill, N.S., Spiegelman, B.M., 1993. Adipose expression of tumor necrosis factor-alpha: direct role in obesitylinked insulin resistance. Science. 259(5091), 87-91. https://doi.org/ $10.1126 /$ science. 7678183

Hu, X.Y., Wu, R.H., Logue, M., Blondel, C., Lai, L., Stuart, B., Flower, A., Fei, Y.T., Moore, M., Shepherd, J., Liu, J.P., Lewith, G., 2017. Andrographis paniculata (Chuān Xīn Lián) for symptomatic relief of acute respiratory tract infections in adults and children: A systematic review and meta-analysis. PLOS One. 12(8), e0181780. https://doi .org/10.1371/journal.pone.0181780

Huang, C., Wang, Y., Li, X., Ren, L., Zhao, J., Hu, Y., Zhang, L., Fan, G., Xu, J., Gu, X., Cheng, Z., Yu, T., Xia, J., Wei, Y., Wu, W., Xie, X., Yin, W., Li, H., Liu, M., ... Cao, B., 2020. Clinical features of patients infected with 2019 novel coronavirus in Wuhan. China. Lancet. 395, 30183-30188. https://doi.org/10.1016/s0140-6736(20)30183-5

Huang, H.Z., Qiu, M., Lin, J.Z., Li, M.Q., Ma, X.T., Ran, F., Luo, C.H., Wei, X.C., Xu, R.C., Tan, P., Fan, S.H., Yang, M., Han, L., Zhang, D.K., 2021. Potential effect of tropical fruits Phyllanthus emblica L. for the prevention and management of type 2 diabetic complications: a systematic review of recent advances. European Journal of Nutrition. 60(7), 3525-3542. https://doi.org/10.1007/ s00394-020-02471-2

Huang, Z., Liu, Y., Qi, G., Brand, D., Zheng, S.G., 2018. Role of vitamin A in the immune system. Journal of Clinical Medicine. 7(9), 258. https://doi.org/10.3390/jcm7090258

Hussein, R.A., El-Anssary, A.A., 2018. The key drivers of the pharmacological actions of medicinal plants, Builders P. H., (Eds.), Plants secondary metabolites. . 10.5772/intechopen.76139

Iacobellis, G., Penaherrera, C.A., Bermudez, L.E., Mizrachi, E.B., 2020. Admission hyperglycemia and radiological findings of SARSCoV2 in patients with and without diabetes. Diabetes Research and Clinical Practice. 164, 108185. https://doi.org/10.1016/j.diabres .2020 .108185

Irshad, M., Chaudhuri, P.S., 2002. Oxidant-antioxidant system: role and significance in human body. Indian Journal of Experimental Biology. 40(11), 1233-1239.

Jalali, A., Dabaghian, F., Akbrialiabad, H., Foroughinia, F., Zarshenas, M.M., 2021. A pharmacology-based comprehensive review on medicinal plants and phytoactive constituents possibly effective in the management of COVID-19. Phytotherapy Research. 35(4), 1925-1938. https://doi.org/10.1002/ptr.6936

Jantan, I., Haque, M.A., Ilangkovan, M., Arshad, L., 2019. An insight into the modulatory effects and mechanisms of action of Phyllanthus Species and their bioactive metabolites on the immune system. Frontiers in Pharmacology. 10, 878. https://doi.org/10.3389/fphar .2019 .00878

Jiang, M., Sheng, F., Zhang, Z., Ma, X., Gao, T., Fu, C., Li, P., 2021. Andrographis paniculata (Burm.f.) Nees and its major constituent andrographolide as potential antiviral agents. Journal of Ethnopharmacology. 272, 113954. https://doi.org/10.1016/j.jep.2021.113954

Joshi, M.B., Lad, A., Prasad, A.S.B., Balakrishnan, A., Ramachandra, L., Satyamoorthy, K., 2013. High glucose modulates IL-6 mediated immune homeostasis through impeding neutrophil extracellular trap formation. FEBS Letters. 587(14), 2241-2246. https://doi.org/10 $.1016 /$ j.febslet.2013.05.053

Kar, P., Kumar, V., Vellingiri, B., Sen, A., Jaishee, N., Anandraj, A., Malhotra, H., Bhattacharyya, S., Mukhopadhyay, S., Kinoshita, M., Govindasamy, V., Roy, A., Naidoo, D., Subramaniam, M.D., 2020. Anisotine and amarogentin as promising inhibitory candidates against SARS-CoV-2 proteins: a computational investigation. Journal of Biomolecular Structure and Dynamics, 1-11. https://doi.org/10 $.1080 / 07391102.2020 .1860133$

Kaushik, S., Dar, L., Kaushik, S., Yadav, J.P., 2021. Identification and characterization of new potent inhibitors of dengue virus NS5 proteinase from Andrographis paniculata supercritical extracts on in animal cell culture and in silico approaches. Journal of Ethnopharmacology. 267, 113541. https://doi.org/10.1016/j.jep.2020.113541

Kazi, S., 2014. Use of traditional plants in diabetes mellitus: A review. International Journal of Pharmacy. 4(4), 283-289.

Keel, S.B., Doty, R.T., Yang, Z., Quigley, J.G., Chen, J., Knoblaugh, S., Kingsley, P.D., Domenico, I.D., Vaughn, M.B., Kaplan, J., Palis, J., Abkowitz, J.L., 2008. A heme export protein is required for red blood cell differentiation and iron homeostasis. Science. 319(5864), 825828. https://doi.org/10.1126/science. 1151133

Khedikar, S.G., Erande, M.P., 2018. Effect of poly-herbal formulation in management of type-II diabetes mellitus. International Journal of Medical Science and Innovative Research. 3(5), 235-240.

Kim, H.Y., Okubo, T., Juneja, L.R., Yokozawa, T., 2010. The protective role of amla (Emblica officinalis Gaertn.) against fructose-induced metabolic syndrome in a rat model. The British Journal of Nutrition. 103(4), 502-512. https://doi.org/10.1017/s0007114509991978

Klimek-Szczykutowicz, M., Szopa, A., Ekiert, H., 2020. Citrus limon (Lemon) phenomenon-a review of the chemistry, pharmacological properties, applications in the modern pharmaceutical, food, and cosmetics industries, and biotechnological studies. Plants. 9(1), 119. https://doi.org/10.3390/plants9010119

Krishnaiah, D., Sarbatly, R., Nithyanandam, R., 2011. A review of the antioxidant potential of medicinal plant species. Food and Bioproducts Processing. 89, 217-233. https://doi.org/10.1016/J.FBP .2010 .04 .008

Kroslak, E., Maliar, T., Nemecek, P., Viskupicova, J., Maliarova, M., Havrlentova, M., Kraic, J., 2017. Antioxidant and proteinase inhibitory activities of selected Poppy (Papaver somniferum L.) genotypes. Chemistry and Biodiversity. 14(9). https://doi.org/10 $.1002 / \mathrm{cbdv} .201700176$

Kurokawa, M., Wadhwani, A., Kai, H., Hidaka, M., Yoshida, H., Sugita, C., Watanabe, W., Matsuno, K., Hagiwara, A., 2016. Activation of cellular immunity in herpes simplex virus type 1 -infected mice by the oral administration of aqueous extract of Moringa oleifera Lam. leaves. Phytotherapy Research. 30(5), 797-804. https://doi.org/ 


\section{$10.1002 /$ ptr.5580}

Kwon, Y.J., Son, D.H., Chung, T.H., Lee, Y.J., 2020. A Review of the pharmacological efficacy and safety of licorice root from corroborative clinical trial findings. Journal of Medicinal Food. 23(1), 12-20. https://doi.org/10.1089/jmf.2019.4459

Lachman, J., Hejtmankova, A., Miholova, D., Kolihova, D., Tluka, P., 2006. Relations among alkaloids, cadmium and zinc contents in opium poppy. Plant, Soil and Environment. 52(6), 282-288. https:// doi.org/10.17221/3442-PSE

Lakshmi, S.S., Kumari, H.V.M., Mohan, S., Meenakumari, R., 2020. Therapeutic effectiveness of the siddha immunomodulatory polyherbal. World Journal of Pharmaceutical Research. 9(7), 712731.

Lee, G.Y., Han, S.N., 2018. The role of vitamin E in immunity. Nutrients. 10(11), 1614-1614. https://doi.org/10.3390/nu10111614

Leone, A., Spada, A., Battezzati, A., Schiraldi, A., Aristil, J., Bertoli, S., 2015. Cultivation, genetic, ethnopharmacology, phytochemistry and pharmacology of Moringa oleifera leaves: An overview. International Journal of Molecular Sciences. 16(6), 12791-12835. https://doi.org/ $10.3390 / \mathrm{ijms} 160612791$

Li, B., Yang, J., Zhao, F., Zhi, L., Wang, Xiqian, Liu, L., Bi, Z., Zhao, Y., 2020. Prevalence and impact of cardiovascular metabolic diseases on COVID-19 in China. Clinical Research in Cardiology. 109, 531-538. https://doi.org/10.1007/s00392-020-01626-9

Li, C., Li, Y., Ding, C., 2019. Molecular sciences the role of copper homeostasis at the host-pathogen axis: from bacteria to fungi. International Journal of Molecular Sciences. 20(1), 175-175. https:// doi.org/10.3390/ijms20010175

Liang, R., Wu, W., Huang, J., Jiang, S., Lin, Y., 2012. Magnesium affects the cytokine secretion of CD4+ T lymphocytes in acute asthma. Journal of Asthma. 49, 1012-1015. https://doi.org/10.3109/ 02770903.2012.739240

Liu, F., Zhu, Y., Zhang, J., Li, Y., Peng, Z., 2020. Intravenous high-dose vitamin $C$ for the treatment of severe COVID-19: Study protocol for a multicentre randomised controlled trial. BMJ Open. 10(7), e039519. https://doi.org/10.1136/bmjopen-2020-039519

Liu, H., Ye, F., Sun, Q., Liang, H., Li, C., Lu, R., Huang, B., Tan, W., Lai, L., 2021. Scutellaria baicalensis extract and baicalein inhibit replication of SARS-CoV-2 and its 3C-like protease in vitro. Journal of Enzyme Inhibition and Medicinal Chemistry. 36(1), 497-503. https://doi.org/10.1080/14756366.2021.1873977

Lu, R., Zhao, X., Li, J., Niu, P., Yang, B., Wu, H., Wang, W., Song, H., Huang, B., Zhu, N., Bi, Y., 2020. Genomic characterisation and epidemiology of 2019 novel coronavirus: implications for virus origins and receptor binding. Lancet. 395, 30251-30259. https:// doi.org/10.1016/S0140-6736(20)30251-8

Lu, S.Y., Chu, Y.L., Sridhar, K., Tsai, P.J., 2021. Effect of ultrasound, high-pressure processing, and enzymatic hydrolysis on carbohydrate hydrolyzing enzymes and antioxidant activity of lemon (Citrus limon) flavedo. LWT. 138, 110511. https://doi.org/10.1016/J.LWT.2020 .110511

Ma, Y., Kosińska-Cagnazzo, A., Kerr, W.L., Amarowicz, R., Swanson, R.B., Pegg, R.B., 2014. Separation and characterization of soluble esterified and glycoside-bound phenolic compounds in dry-blanched peanut skins by liquid chromatography-electrospray ionization mass spectrometry. Journal of Agricultural and Food Chemistry. 62, 11488-11504. https://doi.org/10.1021/jf503836n

Malagi, K., 2018. Impact of herbs on immunomodulation in diabetes mellitus. Journal of Diabetes, Metabolic Disorders and Control. 5(2), 74-76. https://doi.org/10.15406/jdmdc.2018.05.00140

Maret, W., 2017. Zinc in pancreatic islet biology, insulin sensitivity, and diabetes. Preventive Nutrition and Food Science. 22, 1-8. 10.3746/ pnf.2017.22.1.1

Mohiuddin, A.K., 2019. A brief review of traditional plants as sources of pharmacological interests. Open Journal of Plant Science. 4(1), 1008 .

Morvaridzadeh, M., Fazelian, S., Agah, S., Khazdouz, M., Rahimlou, M., Agh, F., Potter, E., Heshmati, S., Heshmati, J., 2020. Effect of ginger (Zingiber officinale) on inflammatory markers: A systematic review and meta-analysis of randomized controlled trials. Cytokine. 135, 155224. https://doi.org/10.1016/j.cyto.2020.155224

Murugan, N.A., Pandian, C.J., Jeyakanthan, J., 2021. Computational investigation on Andrographis paniculata phytochemicals to evaluate their potency against SARS-CoV-2 in comparison to known antiviral compounds in drug trials. Journal of Biomolecular Structure and Dynamics. 39(12), 4415-4426. https://doi.org/10.1080/07391102 .2020 .1777901

Mussard, E., Cesaro, A., Lespessailles, E., Legrain, B., Berteina-Raboin, S., Toumi, H., 2019. Andrographolide, a natural antioxidant: an update. Antioxidants. 8(12), 571. https://doi.org/10.3390/antiox8120571

Nieman, D.C., Wentz, L.M., 2019. The compelling link between physical activity and the body's defense system. Journal of Sport and Health Science. 8(3), 201-217. https://doi.org/10.1016/j.jshs.2018.09.009

Ogurtsova, K., Fernandes, J.D.D.R., Huang, Y., Linnenkamp, U., Guariguata, L., Cho, N.H., Cavan, D., Shaw, J.E., Makaroff, L.E., 2017. IDF Diabetes Atlas: Global estimates for the prevalence of diabetes for 2015 and 2040. Diabetes Research and Clinical Practice. 128, 40-50. https://doi.org/10.1016/j.diabres.2017.03.024

Omar, E.A., Kam, A., Alqahtani, A., Li, K.M., Razmovski-Naumovski, V., Nammi, S., Chan, K., Roufogalis, B.D., Li, G.Q., 2010. Herbal medicines and nutraceuticals for diabetic vascular complications: mechanisms of action and bioactive phytochemicals. Current Pharmaceutical Design. 16(34), 3776-3807. https://doi.org/10.2174/ 138161210794455076

Padayachee, B., Baijnath, H., 2020. An updated comprehensive review of the medicinal, phytochemical and pharmacological properties of Moringa oleifera. South African Journal of Botany. 129, 304-316. https://doi.org/10.1016/j.sajb.2019.08.021

Parasuraman, S., Thing, G.S., Dhanaraj, S.A., 2014. Polyherbal formulation: Concept of ayurveda. Pharmacognosy Reviews. 8(16), 73-80. https://doi.org/10.4103/0973-7847.134229

Patel, R.R., 2020. Tulsi: The queen of medicinal herbs. Journal of Bioequivalence and Bioavailability. 12, 407-407.

Pereira, A., Banegas-Luna, A.J., Peña-García, J., Pérez-Sánchez, H., Apostolides, Z., 2019. Evaluation of the anti-diabetic activity of some common herbs and spices: providing new insights with inverse virtual screening. Molecules. 24(22), 4030-4030. https://doi.org/10.3390/ molecules 24224030

Pingali, U., Ali, M.A., Gundagani, S., Nutalapati, C., 2020. Evaluation of the effect of an aqueous extract of Azadirachta indica (Neem) leaves and twigs on glycemic control, endothelial dysfunction and systemic inflammation in subjects with type 2 diabetes mellitus - a randomized, double-blind, placebo-controlled clinical study. Diabetes, Metabolic Syndrome and Obesity: Targets and Therapy. 13, 4401-4412. https:// doi.org/10.2147/dmso.s274378

Poudel, R.R., Bhusal, Y., Tharu, B., Kafle, N.K., 2017. Role of zinc in insulin regulation and diabetes. Journal of Social Health and Diabetes. 5, 83-87.

Pundarikakshudu, K., Kanaki, N.S., 2019. Analysis and regulation of Traditional Indian Medicines (TIM). Journal of AOAC International. 102(4), 977-978. https://doi.org/10.5740/jaoacint.18-0376

Punthakee, Z., Goldenberg, R., Katz, P., 2018. Definition, Classification and Diagnosis of Diabetes, Prediabetes and Metabolic Syndrome. Canadian Journal of Diabetes. 42(1), 10-15. https://doi.org/10 
$.1016 /$ j.jcjd.2017.10.003

Qin, C., Zhou, L., Hu, Z., Zhang, S., Yang, S., Tao, Y., Xie, C., Ma, K., Shang, K., Wang, W., Tian, D.S., 2020. Dysregulation of immune response in patients with coronavirus 2019 (COVID-19) in Wuhan, China. Clinical Infectious Diseases. 71, 762-768. https://doi.org/ $10.1093 / \mathrm{cid} / \mathrm{ciaa} 248$

Qiu, D., Li, X.N., 2015. Pioglitazone inhibits the secretion of proinflammatory cytokines and chemokines in astrocytes stimulated with lipopolysaccharide. International Journal of Clinical Pharmacology and Therapeutics. 53(9), 746-752. https://doi.org/10.5414/ cp202339

Rabie, A.M., 2021a. Cyanorona-20: The first potent anti-SARS-CoV2 agent. International Immunopharmacology. 98, 107831. https:// doi.org/10.1016/j.intimp.2021.107831

Rabie, A.M., 2021b. Discovery of (E)- N-(4-cyanobenzylidene)- 6-fluoro3-hydroxypyrazine-2 -carboxamide (cyanorona-20): the first potent and specific anti-COVID-19 drug. Chemical Papers, 1-17. https:// doi.org/10.1007/s11696-021-01640-9

Rachmawati, I., 2014. In Vitro immunomodulatory activity of aqueous extract of Moringa oleifera Lam. leaf to the CD4+, CD8+ and B220+ cells in Mus musculus. Journal of Experimental Life Science. 4(1), 15-20. http://dx.doi.org/10.21776/ub.jels.2014.004.01.03

Ragab, D., Eldin, H.S., Taeimah, M., Khattab, R., Salem, R., 2020. The COVID-19 cytokine storm; what we know so far. Frontiers in Immunology. 11, 1446. https://doi.org/10.3389/fimmu.2020 .01446

Rains, J.L., Jain, S.K., 2011. Oxidative stress, insulin signaling, and diabetes. Free Radical Biology and Medicine. 50, 567-575. https:// doi.org/10.1016/J.FREERADBIOMED.2010.12.006

Rambod, M., Rakhshan, M., Tohidinik, S., Nikoo, M.H., 2020. The effect of lemon inhalation aromatherapy on blood pressure, electrocardiogram changes, and anxiety in acute myocardial infarction patients: A clinical, multi-centered, assessor-blinded trial design. Complementary Therapies in Clinical Practice. 39, 101155. https:// doi.org/10.1016/j.ctcp.2020.101155

Read, S.A., Obeid, S., Ahlenstiel, C., Ahlenstiel, G., 2019. The role of zinc in antiviral immunity. Advances in Nutrition. 10, 696-710. https://doi.org/10.1093/advances/nmz013

Rink, L., Gabriel, P., 2000. Zinc and the immune system. The Proceedings of the Nutrition Society. 59, 541-552.

Roncon, L., Zuin, M., Rigatelli, G., Zuliani, G., 2020. Diabetic patients with COVID-19 infection are at higher risk of ICU admission and poor short-term outcome. Journal of Clinical Virology. 127, 104354. https://doi.org/10.1016/j.jcv.2020.104354

Rupp, J.C., Locatelli, M., Grieser, A., Ramos, A., Campbell, P.J., Yi, H., Steel, J., Burkhead, J.L., Bortz, E., 2017. Host cell copper transporters CTR1 and ATP7A are important for Influenza A virus replication. Virology Journal. 14(1), 11. https://doi.org/10.1186/s12985-016 $-0671-7$

Sanlier, N., Gencer, F., 2020. Role of spices in the treatment of diabetes mellitus: A minireview. Trends in Food Science and Technology. 99, 441-449. https://doi.org/10.1016/j.tifs.2020.03.018

Sen, D., Bhaumik, S., Debnath, P., Debnath, S., 2021. Potentiality of Moringa oleifera against SARS-CoV-2: identified by a rational computer aided drug design method. Journal of Biomolecular Structure and Dynamics, 1-18. https://doi.org/10.3390/antiox9020101

Sengupta, P.S., 2020. Use of piper betel to combat COVID19. Prepare@u_general. 1, 1-10. 10.36375/prepare_u.a92

Shaji, D., Yamamoto, S., Saito, R., Suzuki, R., Nakamura, S., Kurita, N., 2021. Proposal of novel natural inhibitors of severe acute respiratory syndrome coronavirus 2 main protease: Molecular docking and ab initio fragment molecular orbital calculations. Biophysical Chemistry.
275, 106608. https://doi.org/10.1016/j.bpc.2021.106608

Sharma, S., Ray, A., Sadasivam, B., 2020. Metformin in COVID-19: A possible role beyond diabetes. Diabetes Research and Clinical Practice. 164, 108183. https://doi.org/10.1016/j.diabres.2020.108183

Singh, A.K., Singh, A., Singh, R., Misra, A., 2020. Remdesivir in COVID-19: A critical review of pharmacology, pre-clinical and clinical studies. Diabetes and Metabolic Syndrome. 14(4), 641-648. https://doi.org/10.1016/j.dsx.2020.05.018

Singh, B.N., Singh, B.R., Singh, R.L., Prakash, D., Dhakarey, R., Upadhyay, G., Singh, H.B., 2009. Oxidative DNA damage protective activity, antioxidant and anti-quorum sensing potentials of Moringa oleifera. Food and Chemical Toxicology. 47(6), 1109-1116. https:// doi.org/10.1016/j.fct.2009.01.034

Singh, M.K., Yadav, S.S., Yadav, R.S., Chauhan, A., Katiyar, D., Khattri, S., 2015. Protective effect of Emblica-officinalis in arsenic induced biochemical alteration and inflammation in mice. SpringerPlus. 4, 438. https://doi.org/10.1186/s40064-015-1227-9

Song, Z., Xu, Y., Bao, L., Zhang, L., Yu, P., Qu, Y., Zhu, H., Zhao, W., Han, Y., Qin, C., 2019. From SARS to MERS, Thrusting Coronaviruses into the Spotlight. Viruses. 11(1), 59. https://doi.org/ $10.3390 / \mathrm{v} 11010059$

Srivastava, V., Yadav, A., Sarkar, P., 2020. Molecular Docking and ADMET study of bioactive compounds of glycyrrhiza glabra against main protease of SARS-CoV2. Materials today. https://doi.org/10 .1016/j.matpr.2020.10.055

Sudhakar, K., Mishra, V., Hemani, V., Verma, A., Jain, A., Jain, S., Charyulu, R.N., 2021. Reverse pharmacology of phytoconstituents of food and plant in the management of diabetes: Current status and perspectives. Trends in Food Science and Technology. 110, 594-610. https://doi.org/10.1016/j.tifs.2020.10.024

Suja, R.S., Nair, A.M.C., Sujith, S., Preethy, J., Deepa, A.K., 2009. Evaluation of immunomodulatory potential of Embolica officinalis fruit pulp extract in mice. Journal of Animal Research. 43, 103-106.

Sun, Z.G., Zhao, T.T., Lu, N., Yang, Y.A., Zhu, H.L., 2019. Research progress of glycyrrhizic acid on antiviral activity. Mini Reviews in Medicinal Chemistry. 19(10), 826-832. https://doi.org/10.2174/ 1389557519666190119111125

Suresh, K., Vasudevan, D.M., 1994. Augmentation of murine natural killer cell and antibody dependent cellular cytotoxicity activities by Phyllanthus emblica, a new immunomodulator. Journal of Ethnopharmacology. 44(1), 55-60. https://doi.org/10.1016/0378 $-8741(94) 90099-\mathrm{x}$

Takooree, H., Aumeeruddy, M.Z., Rengasamy, K., Venugopala, K.N., Jeewon, R., Zengin, G., Mahomoodally, M.F., 2019. A systematic review on black pepper (Piper nigrum L.): from folk uses to pharmacological applications. Critical Reviews in Food Science and Nutrition. 59(sup1), 210-243. https://doi.org/10.1080/10408398 .2019 .1565489

Tan, K.S., Lee, K.O., Low, K.C., Gamage, A.M., Liu, Y., Tan, G.Y., Koh, H.Q., Alonso, S., Gan, Y.H., 2012. Glutathione deficiency in type 2 diabetes impairs cytokine responses and control of intracellular bacteria. The Journal of Clinical Investigation. 122(6), 2289-2300. https://doi.org/10.1172/jci57817

Tessaro, F., Ayala, T.S., Nolasco, E.L., Bella, L.M., Martins, J.O., 2017. Insulin influences LPS-induced TNF- $\alpha$ and IL-6 release through distinct pathways in mouse macrophages from different compartments. Cellular Physiology and Biochemistry. 42(5), 20932104. https://doi.org/10.1159/000479904

Tie, H.T., Tan, Q., Luo, M.Z., Li, Q., Yu, J.L., Wu, Q.C., 2016. Zinc as an adjunct to antibiotics for the treatment of severe pneumonia in children $<5$ years: a meta-analysis of randomised-controlled trials. The British Journal of Nutrition. 115(5), 807-816. https://doi.org/ 


\section{$10.1017 / \mathrm{s} 0007114515005449$}

Trinh, T.A., Park, J., Oh, J.H., Park, J.S., Lee, D., Kim, C.E., Choi, H.S., Kim, S.B., Hwang, G.S., Koo, B.A., Kang, K.S., 2020. Effect of herbal formulation on immune response enhancement in RAW 264.7 macrophages. Biomolecules. 10(3), 424. https://doi.org/10 $.3390 /$ biom 10030424

Ullah, M., Wahab, A., Saeed, S., Khan, S.U., Ali, H., Humayun, S., Abbasi, B.A., Saud, S., Naveed, K., Khan, S.A., Fahad, S., 2021. Coronavirus and its terrifying inning around the globe: The pharmaceutical cares at the main frontline. Chemosphere. 275, 129968-129968. https://doi.org/10.1016/j.chemosphere.2021 .129968

Umar, H.I., Josiah, S.S., Saliu, T.P., Jimoh, T.O., Ajayi, A., Danjuma, J.B., 2021. In-silico analysis of the inhibition of the SARS-CoV-2 main protease by some active compounds from selected African plants. Journal of Taibah University Medical Sciences. 16(2), 162-176. https://doi.org/10.1016/j.jtumed.2020.12.005

Variya, B.C., Bakrania, A.K., Patel, S.S., 2016. Emblica officinalis (Amla): A review for its phytochemistry, ethnomedicinal uses and medicinal potentials with respect to molecular mechanisms. Pharmacological Research. 111, 180-200. https://doi.org/10.1016/ j.phrs.2016.06.013

Walter, T.M., Justinraj, S., Justinraj, C.S., Nandini, V.S., 2020. Effect of nilavembu kudineer in the prevention and management of COVID19 by inhibiting ACE2 Receptor. Siddha Papers. 15(2).

Wang, L., Liang, J., Leung, P.S., 2015. The ACE2/Ang-(1-7)/Mas axis regulates the development of pancreatic endocrine cells in mouse embryos. PLOS One. 10(6), e0128216. https://doi.org/10.1371/ journal.pone.0128216

Wink, M., 2015. Modes of action of herbal medicines and plant secondary metabolites. Medicines (Basel). 2(3), 251-286. https://doi.org/10 $.3390 /$ medicines 2030251
Wittschier, N., Faller, G., Hensel, A., 2009. Aqueous extracts and polysaccharides from liquorice roots (Glycyrrhiza glabra L.) inhibit adhesion of Helicobacter pylori to human gastric mucosa. Journal of Ethnopharmacology. 125(2), 218-223. https://doi.org/10.1016/ j.jep.2009.07.009

Yadav, S.S., Singh, M.K., Singh, P.K., Kumar, V., 2017. Traditional knowledge to clinical trials: A review on therapeutic actions of Emblica officinalis. Biomedicine and Pharmacotherapy. 93, 12921302. https://doi.org/10.1016/j.biopha.2017.07.065

Yarnell, E., 2017. Herbs for viral respiratory infections. Alternative and Complementary Therapies. 24, 35-43. https://doi.org/10.1089/act .2017.29150.eya

Yi, Y.D., Chang, I.M., 2004. An overview of traditional Chinese herbal formulae and a proposal of a new code system for expressing the formula titles. Evidence-based Complementary and Alternative Medicine. 1(2), 125-132. https://doi.org/10.1093/ecam/neh019

Yoon, J., JM, C., SS, H., HK, K., MS, K., JW, J., HP, S., 2019. Fermented milk containing Lactobacillus paracasei and Glycyrrhiza glabra has a beneficial effect in patients with Helicobacter pylori infection: A randomized, double-blind, placebo-controlled study. Medicine (Baltimore). 98(35), e16601. https://doi.org/10.1097/md .0000000000016601

Zhang, J.J., Dong, X., Cao, Y.Y., Yuan, Y.D., Yang, Y.B., Yan, Y.Q., Akdis, C.A., Gao, Y.D., 2020. Clinical characteristics of 140 patients infected with SARS-CoV-2 in Wuhan, China. Allergy. 75(7), 1730 1741. https://doi.org/10.1111/all.14238

Zhang, Y., Li, H., Zhang, J., Cao, Y., Zhao, X., Yu, N., Gao, Y., Ma, J., Zhang, H., Zhang, J., Guo, X., Liu, X., 2020. The clinical characteristics and outcomes of patients with diabetes and secondary hyperglycaemia with coronavirus disease 2019: A single-centre, retrospective, observational study in Wuhan. Diabetes, Obesity and Metabolism. 22(8), 1443-1454. https://doi.org/10.1111/dom .14086 